\title{
Isolation of two developmentally regulated genes involved in spore wall maturation in Saccharomyces cerevisiae
}

\author{
Peter Briza, ${ }^{1,2}$ Michael Breitenbach, ${ }^{2}$ Adi Ellinger, ${ }^{3}$ and Jacqueline Segall ${ }^{1}$ \\ ${ }^{1}$ Department of Biochemistry and Department of Medical Genetics, University of Toronto, Toronto, Ontario M5S 1A8, \\ Canada; ${ }^{2}$ Institut für Mikrobiologie und Genetik, Universität Wien, A-1090 Vienna, Austria ; ${ }^{3}$ Institut für Mikromorphologie \\ und Elektronenmikroskopie, Universität Wien, A-1090 Vienna, Austria
}

\begin{abstract}
During sporulation of Saccharomyces cerevisiae, the four haploid nuclei generated by meiosis are encapsulated within multilayered spore walls. Taking advantage of the natural fluorescence imparted to yeast spores by the presence of a dityrosine-containing macromolecule in the spore wall, we identified and cloned two genes, termed DIT1 and DIT2, which are required for spore wall maturation. Mutation of these genes has no effect on the efficiency of spore formation or spore viability. The mutant spores, however, fail to accumulate the spore wall-specific dityrosine and lack the outermost layer of the spore wall. The absence of this cross-linked surface layer reduces the resistance of the spores to lytic enzymes, to ether, and to elevated temperature. Expression of the DIT and DIT2 genes is restricted to sporulating cells, with the DIT1 transcripts accumulating at the time of prospore enclosure and just prior to the time of dityrosine biosynthesis. Both genes act in a sporeautonomous manner implying that at least some of the activities responsible for forming the outermost layer of the spore wall reside within the developing spore rather than in the surrounding ascal cytoplasm. As the DIT2 gene product has significant homology with cytochrome P-450s, DIT2 may be responsible for catalyzing the oxidation of tyrosine residues in the formation of dityrosine.
\end{abstract}

[Key Words: Saccharomyces cerevisiae; sporulation; spore wall; dityrosine; cytochrome P-450]

Received May 16, 1990; revised version accepted July 17, 1990.

In the yeast Saccharomyces cerevisiae the portion of the life cycle referred to as sporulation consists of meiosis followed by the encapsulation of the haploid nuclei within spore walls. Initiation of sporulation, induced in the laboratory by starvation of MATa/MAT $\alpha$ cells for nitrogen in the presence of a nonfermentable carbon source, is under the control of the key regulatory genes RME1, IME1, and IME2 (Kassir and Simchen 1976; Mitchell and Herskowitz 1986; Kassir et al. 1988; Smith and Mitchell 1989|. A large number of genes involved in meiotic recombination and the segregation of homologous chromosomes have been characterized /Tsuboi 1983; Rockmill and Fogel 1988; Rockmill and Roeder 1988; Hollingsworth and Byers 1989; for reviews, see Esposito and Klapholz 1981; Dawes 1983). After the completion of the two meiotic divisions, spore walls are laid down around the haploid nuclei, generating an ascus containing a tetrad of haploid spores that are more resistant to various lytic enzymes, to some organic solvents, and to high temperature than are vegetative cells (Dawes and Hardie 1974; Put and De Jong 1981). The series of genetic and morphological events that occurs as cells progress through the sporulation pathway has been shown to be accompanied by the sequential activation of temporally distinct classes of sporulation-specific genes (for review, see Magee 1987; Clancy et al. 1983; Kurtz and Lindquist 1984; Percival-Smith and Segall 1984; Weir-Thompson and Dawes 1984; Holaway et al. 1985; Yamashita and Fukui 1985; Gottlin-Ninfa and Kaback 1986; Atcheson et al. 1987; Wang et al. 1987; Law and Segall 1988; Thompson and Roeder 1989|. Here, we describe the identification of two sporulation-specific genes that are required for spore wall maturation.

One of the first events in spore wall formation is the coalescence of vesicles to initiate formation of a flattened double membrane on the cytoplasmic side of the outer spindle plaque; this then expands to envelop the four nuclear lobes budding off from the parental nucleus (for review, see Byers 1981; Moens 1971). Spore wall components are then deposited between this double membrane (Lynn and Magee 1970). Electron microscopic analysis of the mature spore wall reveals four layers (Kreger-van Rij 1978). The two inner layers, consisting mainly of glucans and mannans, are similar in composition to the vegetative cell wall and often appear as a single layer (Katohda et al. 1984; Briza et al. 1988). Next is a layer containing glucosamine with $95 \%$ being polymerized into chitosan and $5 \%$ into chitin (Briza et al. 1988). This layer and the outermost layer, which is very thin and osmiophilic, are thought to confer the protec- 
tive nature on the spore wall. Spores produced by glucosamine auxotrophs lack these two outermost layers of the spore wall and are sensitive to lytic enzymes such as Glusulase and zymolyase (Ballou et al. 1977).

Although detailed characterization of the molecular composition of the spore wall has been hindered by the insoluble nature of this structure, analysis of an acid hydrolysate of purified spore walls led to the discovery that dityrosine comprises 20 mole-percent of the amino acid content of the spore wall (Briza et al. 1986). The crosslinked tyrosine, which arises only during sporulation, is present in an insoluble macromolecule and exists as both $L L$ and $D L$ stereoisomers (Briza et al. 1990). Crosslinking of tyrosine also occurs in other insoluble structures such as the insect cuticle (Andersen 1964) and the fertilization membrane of the sea urchin egg (Foerder and Shapiro 1977). Although horseradish peroxidase will cross-link tyrosine residues in vitro and a peroxidase has been shown to be responsible for the formation of dityrosine in the fertilized sea urchin egg (Foerder and Shapiro 1977), no significant peroxidase activity can be detected during sporulation in yeast (P. Briza, unpubl.). To gain insight into the mechanism of tyrosine crosslinking in yeast and to allow further characterization of the cross-linked macromolecule, we isolated mutants that initiate spore wall formation but fail to synthesize dityrosine.

\section{Results}

\section{Isolation of mutants defective in spore wall maturation}

The deposition of a dityrosine-containing macromolecule in the outermost layers of the yeast spore wall imparts a bluish fluorescence to the spores (Briza et al. 1986). We took advantage of this fluorescence, which provides a useful tag to assess the completion of sporulation, to devise a screen aimed at identifying sporulation mutants specifically defective in spore wall maturation (see Materials and methods). To allow the identification of recessive mutations, we used the haploid strain PB2-1C (MATa spo13-1 sir4ts trp1-1 leu2 his6) (Briza 1987) for this screen. Although usually only diploid $M A T \mathbf{a} / M A T \alpha$ cells are able to sporulate, PB2-1C can initiate sporulation because mutation of SIR4 effectively leads to mating type heterozygosity due to expression of the otherwise silent $H M L$ and $H M R$ loci (Herskowitz and Oshima 1981). This haploid strain is also able to successfully complete sporulation generating two viable haploid spores, as the presence of the spo13-1 allele restricts meiosis to a single division (Wagstaff et al. 1982).

We first identified mutants that formed dityrosine-deficient colonies on sporulation medium as assessed by their lack of fluorescence. To eliminate those mutants that might be blocked in early events of the sporulation pathway and might therefore only indirectly be prevented from forming spore walls, we then discarded those mutants that failed to form visible asci as assessed by light microscopy. In this way, we isolated eight independent mutants that completed early events of spore formation but generated spores that failed to emit the fluorescence diagnostic of the spore wall-specific dityrosine (Fig. 1A). High performance liquid chromatography (HPLC) fractionation of an acid hydrolysate of cells transferred to sporulation medium confirmed that the spores of all eight mutant strains contained greatly reduced amounts of dityrosine (for an example, see Fig. 1B). We have named the eight mutant alleles dit101dit108 to reflect the dityrosine-deficient nature of the mutant spores. Quantitation of the amount of residual dityrosine by fluorescence spectrophotometric analysis indicated that the level of dityrosine in strains containing the dit101 or dit105 alleles was $\sim 8 \%$ of that in
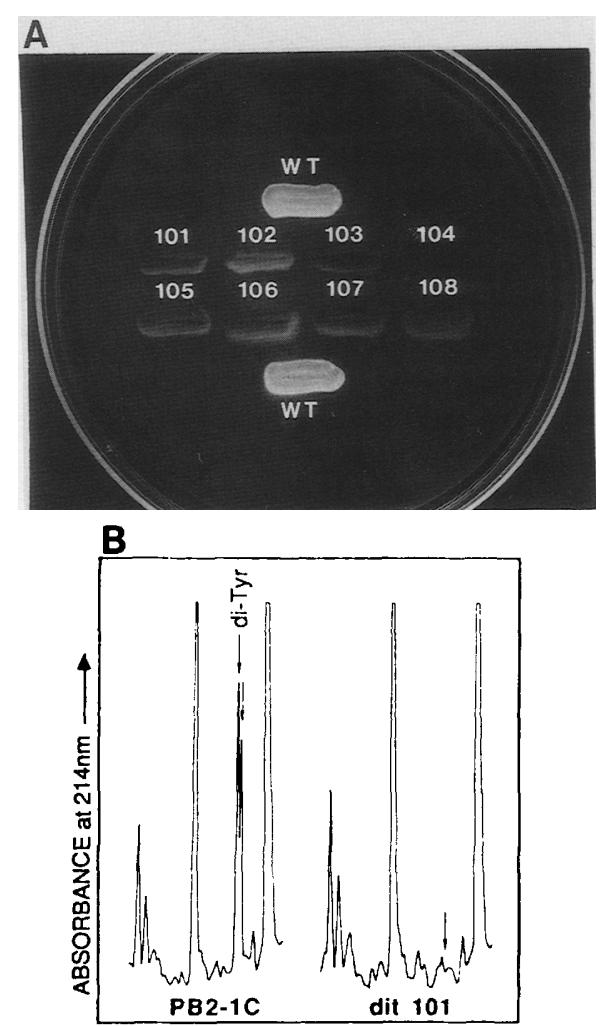

Figure 1. Mutant ascospores fail to fluoresce and are deficient in dityrosine. $(A)$ Sporulated colonies of wild-type cells (top and bottom rows) and the eight Dit $^{-}$mutants (two middle rows) were treated as described in Materials and methods and then examined under UV light for fluorescence. Approximately $30 \%$ of the cells in each colony had formed asci. $(B)$ Acid hydrolysates of sporulated cultures of wild-type cells (PB2-1C) and the mutant strain containing the dit101 allele were fractionated by HPLC (see Materials and methods). The absorbance peaks diagnostic of dityrosine in the fractions from the wild-type culture are indicated by the arrows (di-Tyr). The peak appears as a doublet due to the presence of both $D L$ - and $L L$-dityrosine. The fractions in this region were then subjected to fluorescence spectrophotometric analysis to quantitate the amount of dityrosine. The arrow in the HPLC elution profile of the hydrolysate of the mutant cells indicates the expected position for elution of dityrosine. The fractions in this region were also analyzed by fluorescence spectrophotometry to quantitate the amount of residual dityrosine. 
the wild-type strain, whereas the corresponding levels were $4 \%$ in the strain containing dit108 and $0.1-0.8 \%$ in the strains containing dit102, dit103, dit104, dit106, or dit107.

Preliminary examination of these eight mutants indicated that they behaved like wild-type cells during vegetative growth and produced viable asci as efficiently as did the parental strain upon transfer to sporulation medium. However, we discovered that the spores of all eight mutant strains were unusually sensitive to Glusulase, a mixture of lytic enzymes prepared from snail intestinal juice. Although the vegetative cell wall and the ascal cell wall are rapidly degraded by Glusulase, wildtype spore walls are extremely resistant to digestion. The observation that resuspension of the mutant asci in a solution of Glusulase led to rapid lysis of the spores (see below) supported the presumption that the mutant strains were defective in spore wall maturation.

To gain further insight into the nature of the defects in the $\mathrm{Dit}^{-}$strains, we compared the structure of the mu- tant spore walls with that of wild-type spore walls by electron microscopy. A typical wild-type ascus is depicted in Figure 2 (upper left). The outermost surface of the spore wall, which appears as a thin and very osmiophilic layer, and the underlying, more diffuse, chitosancontaining layer are spore-specific, whereas the innermost layers resemble the vegetative cell wall. Inspection of electron micrographs of sporulated cells of the mutant strains indicated that the dit102-dit108 alleles led to spores that lacked the outermost, thin, and osmiophilic layer of the spore wall, whereas mutation of the dit101 allele led to spores lacking both outer layers of the spore wall (Fig. 2 and data not shown).

Consistent with the defects in the structure of the spore wall in the Dit ${ }^{-}$mutants as visualized in the electron micrographs, we found that primulin, a chitin-specific fluorescent dye that stains wild-type asci inefficiently, stained all the mutant asci with the exception of those produced by the strain containing the dit 101 allele (data not shown). Previous studies have shown that the
WT

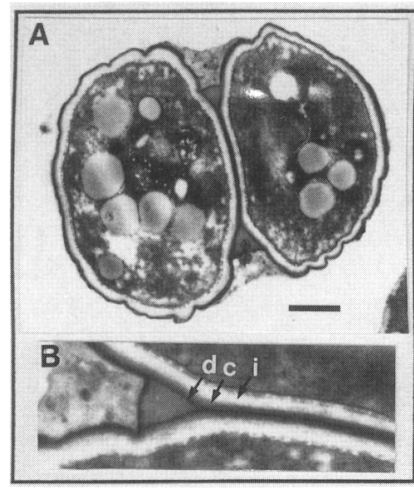

$\operatorname{dit} 101$

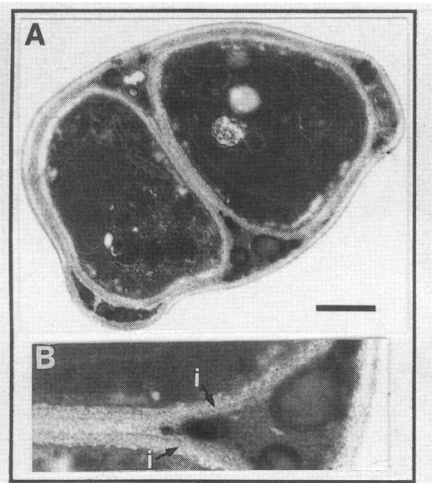

$\operatorname{dit} 104$

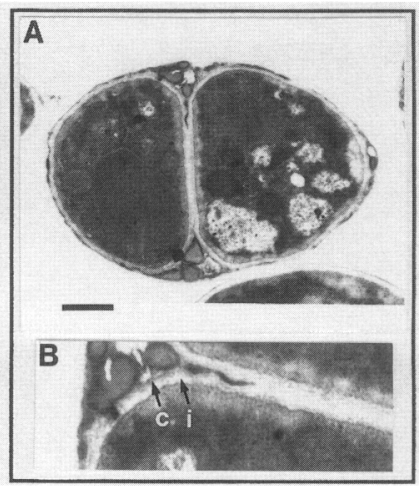

$\operatorname{dit} 107$

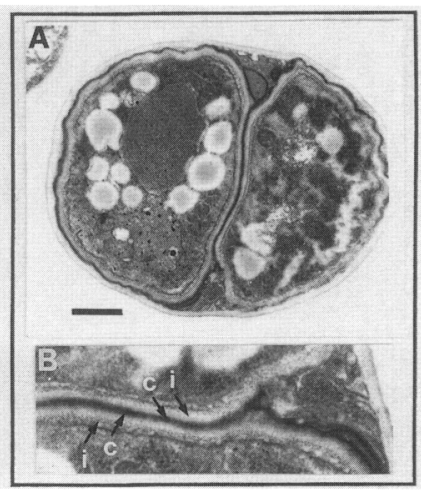

+ /dit101

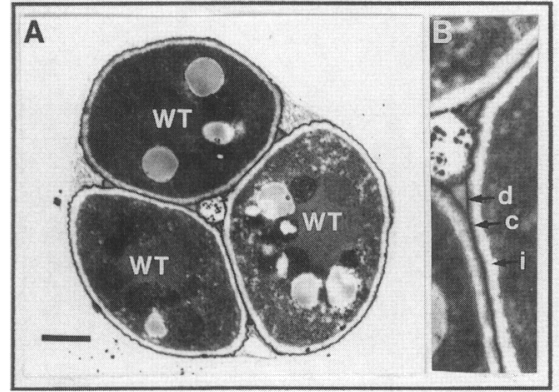

+/dit104

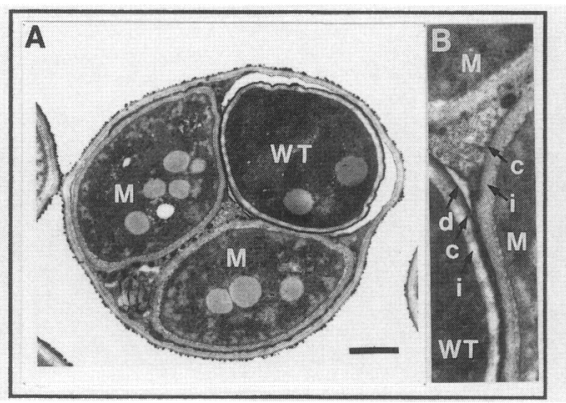

+/dit107

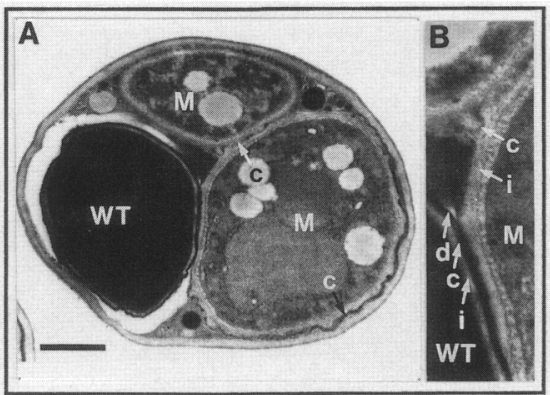

Figure 2. Electron microscopic analysis of mutant asci. (A) A typical ascus is depicted for the haploid wild-type strain PB2-1C (WT), the haploid mutant strains containing the dit101, dit104, and dit107 alleles and the heterozygous diploid strains $+/$ dit101, $+/$ dit104, and +/dit107 obtained by mating the strains containing the dit101, dit104, and dit107 alleles, respectively, with a wild-type strain (SHU32). (WT) Wild-type spore; (M) mutant spore. Note that sporulation of PB2-1C (MAT $\alpha$ spo13-1 sir4 trp1-1 leu2 his6) produces asci containing two haploid spores and that sporulation of the diploid strains (MATa/MAT $\alpha$ sir4/SIR4 $\operatorname{dit}^{-} / D I T^{+}$spo13/SPO13) produces asci containing four haploid spores. The electron micrographs of the four-spored asci rarely show more than three spores within one plane as a result of the tetrahedral arrangement of the spores. Bars, $1 \mu \mathrm{m}$. (B) A portion of the spore wall of each ascus is shown at increased magnification relative to $A$. The wild-type spore wall contains four layers (see Introduction). The outermost, thin, and very dark layer is denoted with the arrow labeled $d$. The underlying chitosan-containing layer is denoted with the arrow labeled $c$. Occasionally, this layer appears to be fragmented (see Discussion). The two inner layers, which often appear as a single layer, are denoted with the arrow labeled $i$. Because of differences in staining properties, wild-type spores sometimes appear darker than mutant spores. 
outermost layer of the spore wall prevents primulin from staining the underlying chitosan layer, presumably because the dye is unable to penetrate the outermost layer (Briza et al. 1988). The absence of this outermost layer in spores mutant for the dit102-dit108 alleles might make the chitosan layer more freely accessible to primulin. The inability to stain spores produced by the strain containing the dit101 allele presumably reflects not only the absence of the dityrosine-containing surface layer but also the underlying chitosan layer.

Assessment of the phenotype of heterozygous diploid strains revealed that six of the dit alleles represented genes that behaved in a spore autonomous manner. For this analysis each mutant strain was mated with a wildtype haploid strain, and the resulting diploid strain was sporulated. Sporulation of diploid strains heterozygous for dit102, dit103, dit104, dit106, dit107, or dit108 yielded asci that displayed phenotypic segregation of the spore wall defect. Thus, two spores in each ascus were Glusulase sensitive and two spores were Glusulase resistant. As assessed by electron microscopic examination, two spores in each ascus lacked the outermost layer of the spore wall, whereas two spores had wildtype spore walls (for examples, see Fig. 2). In contrast to the lack of complementation between the wild-type and mutant alleles of these spore autonomous genes, dit101 and dit105 behaved as recessive mutations. Sporulation of the diploid heterozygous strains MATa dit101/MAT $\alpha$ DIT101 and MATa dit105/MAT $\alpha$ DIT105 generated only phenotypically wild-type spores, all four spores present in an ascus being Glusulase resistant and containing mature spore walls as assessed by electron microscopy (for an example, see Fig. 2). In the present study, we focused on characterization of the six spore-autonomous mutations, dit102-dit104 and dit106-dit108.

A

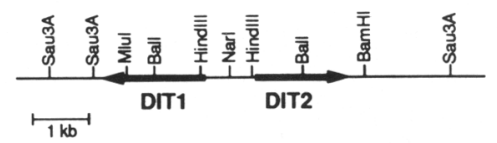

pPB-10

pPB-20

pPB-18

pPB-17

pPB-13

PPB-30

pPB-12

pPB-11

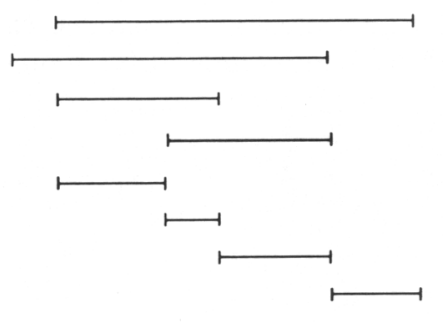

Cloning the DIT1 and DIT2 genes by complementation

Complementation analysis of the mutant alleles by standard genetic techniques was complicated by the Glusulase-sensitive nature of the mutant spores. Additionally, the spore-autonomous behavior of the alleles made it difficult to outcross the mutations. We therefore decided to compare the mutations by cloning the corresponding wild-type genes. A yeast DNA library, constructed by Nasmyth and Tatchell (1980), was screened for plasmids that would restore fluorescence to sporulated cultures of the mutant cells (see Materials and methods). The plasmid denoted pPB-10 (Fig. 3A), which was first isolated by complementation of the dit $102 \mathrm{mu}$ tation, was reisolated on screening for complementation of the dit103 and dit106 mutations. A plasmid denoted pPB-20 (Fig. 3A) with a yeast DNA insert that largely overlapped that of pPB-10 was isolated by complementation of the dit104 mutation. We then tested these two plasmids for their ability to complement each of the six spore-autonomous mutations. Although each plasmid could complement all six mutations, we found that subclone pPB-18 could complement only the dit103, dit104, and dit108 alleles and that subclone pPB-17 could complement only the dit102, dit106, and dit107 alleles (Fig. $3 \mathrm{~A})$. This suggested that the six dit mutations defined two closely linked genes. We refer to these genes as DIT1, defining the complementation group containing the dit103, dit104, and dit108 alleles, and DIT2, defining the complementation group containing the dit102, dit106, and dit107 alleles. As the slightly smaller nonoverlapping clones pPB-12 and pPB-13 (Fig. $3 \mathrm{~A})$ were unable to complement any mutant allele, the $D I T 1$ and DIT2 genes must be very closely linked.

The presence of the two contiguous DIT genes was

\section{COMPLEMENTATION}

$$
\begin{array}{rrrrrr}
102 & 103 & 104 & 106 & 107 & 108 \\
+ & + & + & + & + & + \\
+ & + & + & + & + & + \\
- & + & + & - & - & + \\
+ & - & - & + & + & - \\
- & - & - & - & - & - \\
- & - & - & - & - & - \\
- & - & - & - & - & - \\
- & - & - & - & - & -
\end{array}
$$

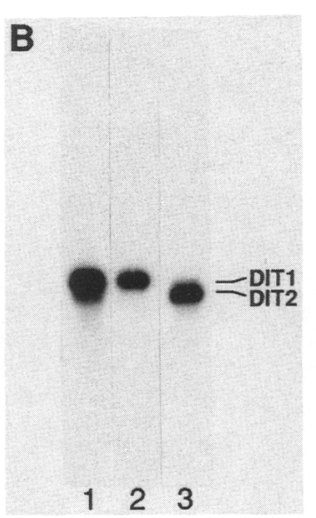

Figure 3. Isolation of the DIT1 and DIT2 genes. $(A)$ Plasmids pPB-10 and pPB-20 were isolated by screening a yeast DNA library for plasmids that could complement the nonfluorescent defect of various Dit- mutants (see Results). Portions of the yeast DNA insert of pPB-10 were subcloned into YEp13 generating pPB-11, pPB-12, pPB-13, pPB-17, pPB-18, and pPB-30. The yeast DNA fragment present in each of these plasmids is denoted beneath the map of the DIT1-DIT2 region. The arrows on this map denote the open reading frames corresponding to DIT1 and DIT2 (Fig. 7). Each of these plasmids was tested for its ability to complement the dit102-dit104 and dit106-dit108 alleles by transforming the replicating plasmids into the various mutants and then testing sporulated colonies of the transformed cells for fluorescence. The results of this analysis are indicated in the table denoted COMPLEMENTATION. $(B)$ Poly $(A)^{+}$ RNA isolated from MATa/MAT $\alpha$ cells at $12 \mathrm{hr}$ after transfer to sporulation medium was separated on a $1.5 \%$ agarose gel and transferred to a nylon membrane. Adjacent strips cut from this filter were hybridized with radioactively labeled pEMBL19 derivatives containing the yeast DNA insert of pPB-10 (lane 1), pPB-13 (lane 2), and pPB-12 (lane 3). The filter of lane 3 was exposed four times longer than the filters of lanes 1 and 2 to compensate for the lower level of DIT2 transcripts. 
confirmed by Northern analysis. RNA isolated from wild-type sporulating cells was separated by gel electrophoresis and transferred to a nylon membrane. A radioactively labeled pEMBL19 derivative containing the yeast DNA insert of pPB-10 hybridized with two transcripts, a relatively abundant $1.9-\mathrm{kb}$ transcript and a less abundant 1.6-kb transcript (Fig. 3B, lane 1). Hybridization with radioactively labeled probes prepared with subcloned DNA sequences indicated that the DIT1 gene encodes the $1.9-\mathrm{kb}$ transcript and that the DIT2 gene encodes the less abundant 1.6-kb transcript (Fig. 3B, lanes 2 and 3 ).

As the yeast DNA library had been prepared in a highcopy $2 \mu$-based vector, we subcloned the yeast DNA insert of pPB-10 into a low-copy centromere-containing plasmid. We found that the low-copy plasmid also complemented the dit alleles, suggesting that the putative cloning of DIT DNA did not result simply from the suppression of the dit mutations by an increased dosage of an alternative gene product.

\section{Mutational analysis of the DIT1 and DIT2 genes}

To exclude the possibility that the cloned DNA represented an extragenic suppressor, we then verified that the DIT DNA contained the wild-type alleles of the original dit mutations. An approach frequently used for such verification is to use the cloned DNA to direct integration of a selectable marker at the chromosomal locus corresponding to the cloned sequence and to test for linkage between the selectable marker and the locus defined by mutation. However, this approach was not feasible with the DIT DNA as the Glusulase-sensitive nature of the dit spores rendered standard tetrad analysis difficult. We therefore decided to base our analysis on the phenotypes of cells containing disruptions of the DIT genes and the frequencies of recombination between these disrupted genes and the original mutations.

Mutations were introduced into the chromosomal DIT1 and DIT2 genes as follows. First, a yeast DNA fragment containing the URA3 gene was inserted into the coding region of the cloned DIT1 gene, and a linear DNA fragment containing the disrupted gene was used to transform MATa ura3 and MATa ura3 cells to $\mathrm{Ura}^{+}$ (see Materials and methods). MATa dit1 :: URA3 and $M A T \alpha$ dit1 :: URA3 transformants were then mated to obtain a homozygous mutant diploid strain. The same procedure was used to obtain a MATa dit2 :: URA3/ $M A T \alpha$ dit2 :: URA3 strain. Southern blot analysis of genomic DNA confirmed that the chromosomal copies of the genes had been replaced with the corresponding disrupted copies (data not shown). We refer to these mutant alleles of DIT1 and DIT2 as dit1-1 and dit2-1, respectively. We then sporulated the disruption homozygotes and examined the phenotype of the resulting asci. As expected, the spores produced by both mutant strains were sensitive to Glusulase and were deficient in dityrosine, containing $<0.05 \%$ of the amount present in wildtype spores, as assessed by spectrofluorometric analysis of HPLC-purified dityrosine (data not shown). Electron microscopic examination revealed that all four spores present within asci of either strain lacked the outermost layer of the spore wall (Fig. 4). As expected from the spore autonomous behavior of the original dit alleles, heterozygous MATa DIT1/MAT $\alpha$ dit1-1 and MATa DIT2/MAT $\alpha$ dit2-1 strains produced asci containing two wild-type spores and two spores lacking the outermost surface layer of the spore wall (Fig. 4). Consistent with the visualization of the chitosan-containing layer in electron micrographs of the mutant spores (Fig. 4B), we found that these spores could be stained readily with primulin (Fig. 4C). As a further test for the presence of the chitosan layer in the mutant spores, we measured the glucosamine content of hydrolysates of sporulated cultures. We found that the glucosamine content of sporulated cells of both homozygous mutants, MATa dit1-1/MAT $\alpha$ dit1-1 and MATa dit2-1/MAT $\alpha$ dit2-1, was comparable to that of sporulated wild-type cells, increasing approximately fourfold during sporulation (Table 1). Most of the glucosamine was present in the insoluble fraction of a lysate of sporulated cells, suggesting that it was polymeric and associated with the spore walls (Table 1). The observation that the glucosamine was degraded by $\mathrm{HNO}_{2}$ confirmed that the glucosamine was present mostly as chitosan rather than as chitin (Table 1).

We then mated the original strains containing dit103, dit104, and dit108, presumptive alleles of DIT1, with the MATa dit1-1 strain. The original mutant strains containing dit102, dit106, and dit107, presumptive alleles of DIT2, were mated with the MATa dit2-1 strain. We found that sporulated cultures of each of the six resulting diploid strains contained only trace amounts of dityrosine (data not shown). Moreover, electron microscopic examination of $>500$ asci from both the MATa dit1-1/MAT $\alpha$ dit104 and the MATa dit2-1/MAT $\alpha$ dit106 strains failed to reveal any spores containing the outermost layer of the spore wall (data not shown). Because the phenotype of the mutant strains constructed using the cloned DIT genes was indistinguishable from that of the original mutants and because no recombination was observed between the original dit alleles and the disruption mutations, we concluded that the DIT genes isolated by complementation represent the wild-type alleles of the original mutations.

\section{Mutation of DIT1 or DIT2 leads to less hardy spores}

Because the MATa dit1-1/MATa dit1-1 and MATa dit2-1/MATa dit2-1 strains sporulated more efficiently than did the original PB2-1C-derived mutant strains, we took advantage of these newly constructed homozygotes to examine the phenotype of the $\mathrm{Dit}^{-}$mutants in more detail. First, we confirmed our qualitative observations that mutation of either the DIT1 gene or the DIT2 gene led to Glusulase sensitivity of the mutant spores. Greater than $90 \%$ of MATa dit1-1/MAT $\alpha$ dit1-1 spores and MATa dit2-1/MATa dit2-1 spores lysed after a 30min exposure to Glusulase (Fig. 5A). Wild-type spores, treated in the same way, remained intact. We then examined the viability of the mutant spores. As the Glusulase-sensitive nature of the mutant spores made te- 
Briza et al.
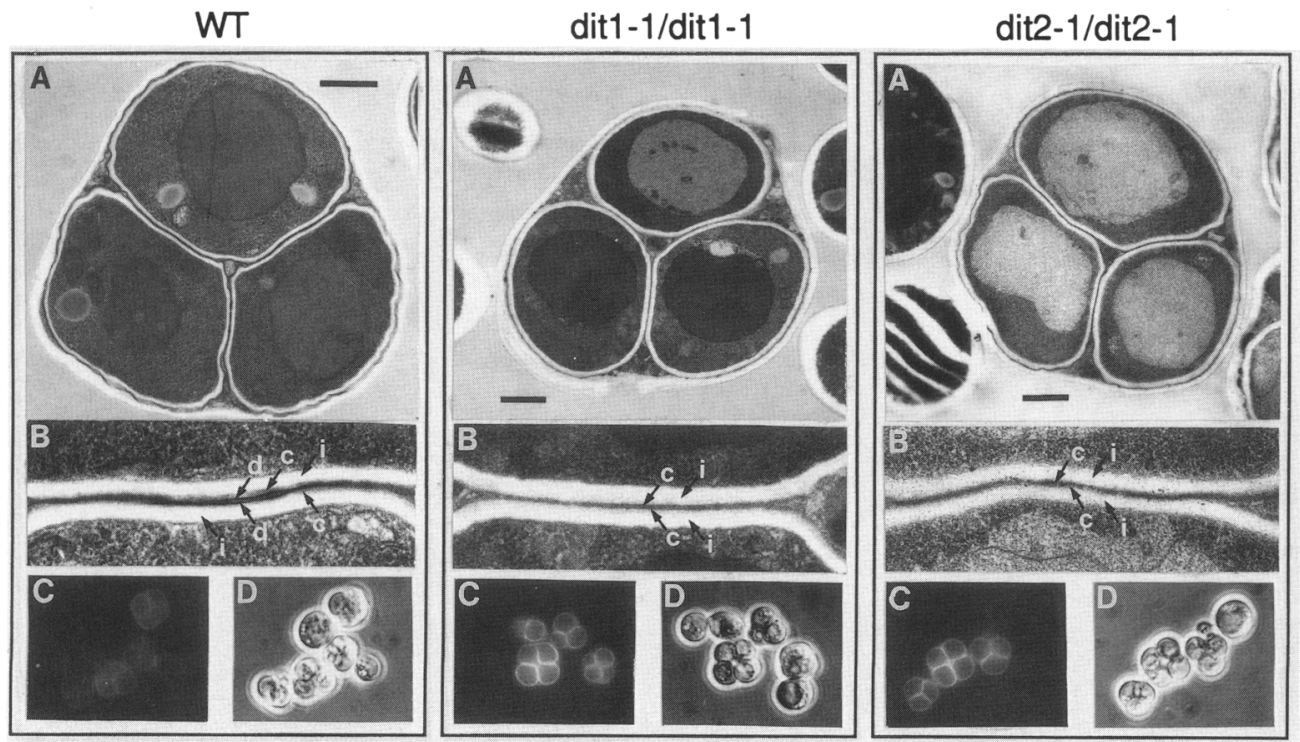

$+/$ dit1-1
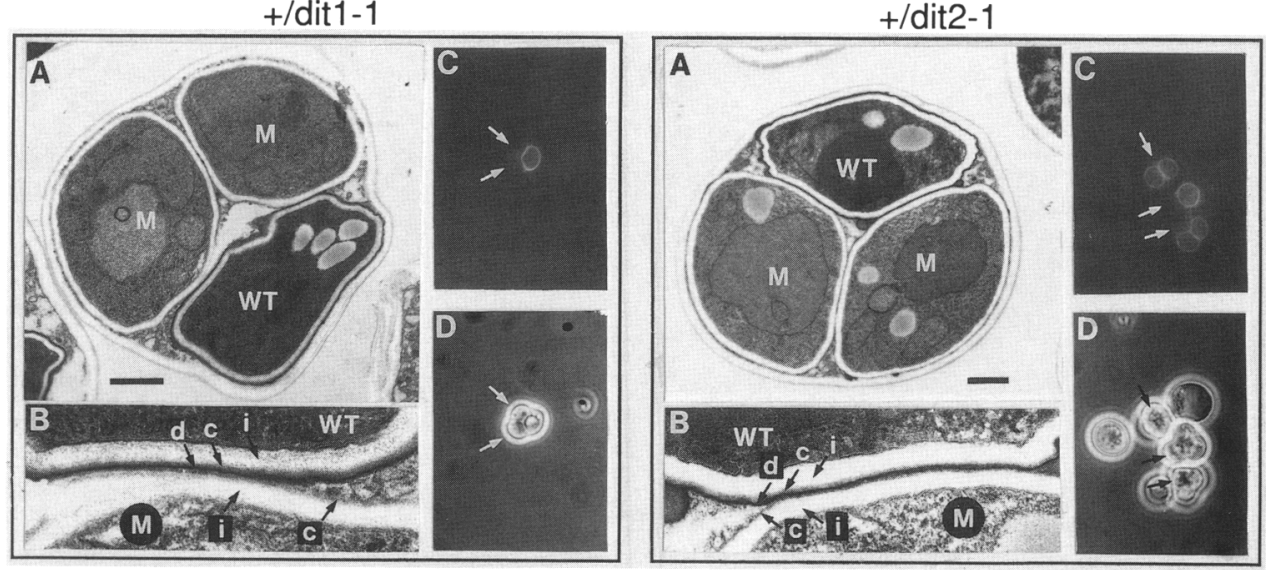

Figure 4. Electron microscopy and fluorescence microscopy of asci of strains containing the dit1-1 and dit2-1 alleles. $(A)$ An electron micrograph of a typical ascus is shown for the wild-type diploid strain LP-HT (WT), the homozygous diploid MATa dit1-1/MAT $\alpha$ dit1-1 (dit1-1/ditl-1) and MATa dit2-1/MAT $\alpha$ dit2-1 (dit2-1/dit2-1) strains, and the heterozygous diploid MATa DIT1/MATa dit1-1 $(+/$ dit $1-1)$ and $M A T \alpha$ DIT2/MAT $\alpha$ dit2-1 $(+/$ dit2-1) strains. The layers of the spore wall are denoted as in Fig. 2 . Bars, $1 \mu \mathrm{m} .(B) \mathrm{A}$ portion of the spore wall from each ascus is shown at increased magnification relative to $A$. Fluorescent $(C)$ and phase-contrast $(D)$ microscopic analyses of primulin-treated sporulated cultures. Efficient primulin staining of the chitosan-containing layer of the spore wall occurs only if the outermost layer of the spore wall is absent. Nonfluorescent wild-type spores in heterozygous asci are indicated with an arrow.

trad dissection difficult, we estimated spore viability by determining the plating efficiency of sporulated cultures of the homozygous mutant strains $72 \mathrm{hr}$ after transfer to sporulation medium. The plating efficiencies of mutant and wild-type cells were indistinguishable $(85-90 \%)$.

We then tested whether the loss of the outermost layer of the spore wall affected the resistance of spores to ether or to elevated temperature. As shown in Figure 5B, asci of the mutant strains MATa dit1-1/MATa dit1-1 and MATa dit2-1/MAT $\alpha$ dit2-1 were 100-fold more sensitive to an 8-min exposure to ether than were asci of the wild-type strain. The mutant asci were almost as sensitive to ether as stationary-phase cells were. The thermotolerance of the mutant spores was examined by exposing cultures of sporulated cells to $55.5^{\circ} \mathrm{C}$ for various periods of time. We found that asci of the mutant strains
MATa dit1-1/MATa dit1-1 and MATa dit2-1/MAT $\alpha$ dit2-1 were significantly more sensitive to elevated temperature than wild-type asci were (Fig. 5C). Survival of the mutant asci was, however, higher than stationaryphase cells treated in the same manner (Fig. 5C). Correlation of these phenotypic effects of the dit mutations with the effect of the mutations on the structure of the spore wall suggests that the outermost cross-linked layer of the spore wall is responsible for the resistance of the spore to Glusulase and to ether and contributes to the heat resistance of spores.

Sporulation-specific expression of the DIT1 and DIT2 genes

Several studies have revealed that expression of many 
Table 1. Glucosamine content of wild-type and mutant spore walls

\begin{tabular}{|c|c|c|c|c|}
\hline \multirow[b]{3}{*}{ Strain } & \multicolumn{4}{|c|}{ D-Glucosamine } \\
\hline & \multicolumn{2}{|c|}{$\begin{array}{c}\mu \mathrm{mole} / 10^{10} \\
\text { cells }^{\mathrm{a}}\end{array}$} & \multirow{2}{*}{$\begin{array}{l}\text { percent in } \\
\text { cell and } \\
\text { spore walls }\end{array}$} & \multirow{2}{*}{$\begin{array}{c}\text { percent } \\
\text { in chitosanc }\end{array}$} \\
\hline & veg & spo & & \\
\hline WT & 8.5 & 30.5 & 85 & 81 \\
\hline $\operatorname{dit} 1-1 / \operatorname{dit} 1-1$ & 7.5 & 27.5 & 84 & 83 \\
\hline $\operatorname{dit} 2-1 / \operatorname{dit} 2-1$ & 11.2 & 36.0 & 88 & 70 \\
\hline
\end{tabular}

${ }^{a}$ Glucosamine was determined in total cell hydrolysates, using a modified Morgan-Elson procedure as described by Ballou et al. (1977).

bCells of a sporulated culture were disrupted by agitation with glass beads, and soluble and cell wall fractions, obtained by low-speed centrifugation, were assayed for glucosamine.

cThe sensitivity of chitosan to degradation by $\mathrm{HNO}_{2}$ was used to distinguish between chitin and chitosan. The glucosamine content of the $\mathrm{HNO}_{2}$ insoluble fraction of the cell walls was subtracted from the total glucosamine content of the cell walls to estimate the percentage of glucosamine present in chitosan (Briza et al. 1988).

genes encoding sporulation-specific functions is developmentally regulated. To examine the developmental specificity of expression of the DIT genes, filters containing poly $(\mathrm{A})^{+}$RNA purified from MATa/MATa, $M A T \mathbf{a} / M A T \alpha$, and $M A T \alpha / M A T \alpha$ cells during vegetative growth and at various times after transfer to sporulation medium were hybridized with radioactively labeled DIT DNA. We found that the DIT transcripts accumulated only in MATa/MAT $\alpha$ cells in sporulation medium (Fig. 6A). Transcripts were not detected in RNA from vegetatively growing cells (Fig. 6B, and data not shown) nor in RNA extracted from the asporogenous MATa/

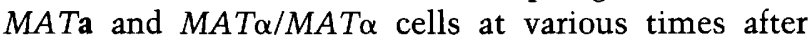
transfer to sporulation medium (Fig. 6A, and data not shown). Consistent with the presumed involvement of the DIT genes in spore wall maturation, transcripts corresponding to the DIT1 and DIT2 genes began to accumulate at $8-10 \mathrm{hr}$ after the transfer of cells to sporulation medium, just prior to the time at which dityrosine began to accumulate (Fig. 6C). The time of maximal DIT transcript accumulation, $12-14 \mathrm{hr}$ of sporulation, corresponded to the time span at which immature asci could be detected by light microscopy and maximal dityrosine synthesis occurred (Fig. 6C). The DIT transcripts disappeared from sporulating cells as mature spores began to appear (Fig. 6C).

Previously, we characterized two temporally distinct classes of sporulation-specific (SPS) genes, referred to as middle and late genes, which are expressed during the later phases of the sporulation program (Percival-Smith and Segall 1984; Law and Segall 1988). Transcripts corresponding to middle SPS genes, represented in Figure 6B by the SPS1 and SPS2 genes, can be detected between 8 and $14 \mathrm{hr}$ after transfer of cells to sporulation medium. Transcripts corresponding to the late SPS genes, represented in Figure 6B by the SPS100 gene, begin to accumulate at $14 \mathrm{hr}$ of sporulation and then remain at a constant level. Comparison of the temporal pattern of ex- pression of the DIT genes with the expression of the SPS genes revealed that the DIT genes were first expressed after the middle SPS genes had been turned on but prior to the time of late SPS gene transcription (Fig. 6B). Thus, the DIT genes define a new temporal class of sporulation-specific genes. It is interesting to note that the time of activation of these SPS genes correlates with the time of action of their gene products. Mutation of the SPS1 gene blocks sporulation after the completion of meiosis such that mutant cells become tetranucleate but fail to form spore walls (Percival-Smith and Segall 1986). As described here, strains with a mutation of either the DIT1 gene or the DIT2 gene are able to complete prospore enclosure but fail to deposit the outermost layer of the spore wall. Mutation of the SPS100 gene delays, but does not prevent, spore wall maturation (Law and Segall 1988).

\section{Nucleotide sequence of the DIT1 and DIT2 genes}

As a first step in elucidating the function of the DIT genes, we determined the nucleotide sequence of the yeast DNA insert present in plasmid pPB-10. As expected, this revealed the presence of two open reading frames (ORF) (Figs. 3A and 7). The two ORFs are sepa-

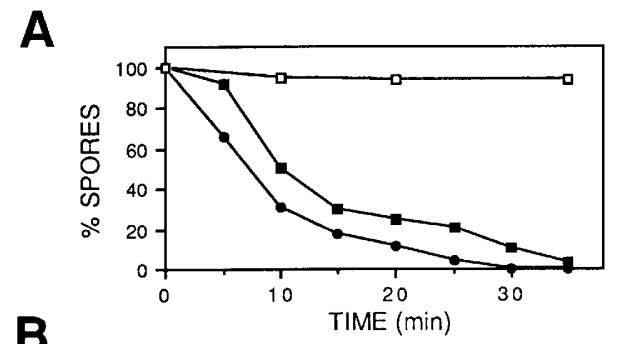

B
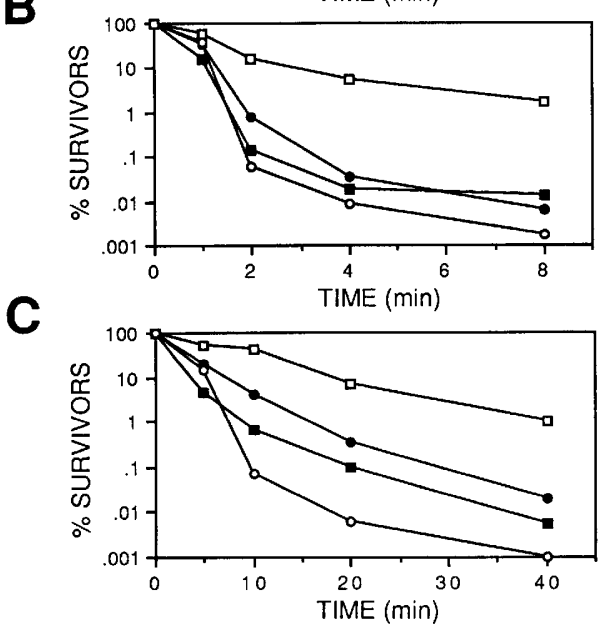

Figure 5. Mutation of the DIT1 or the DIT2 gene leads to less hardy spores. A sporulated culture of MATa/MATa cells ( $\square$ ), a

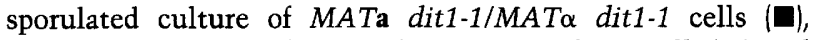
a sporulated culture of MATa dit2-1/MAT $\alpha$ dit2-1 cells (O), and a stationary-phase culture of MATa/MAT $\alpha$ cell $(O)$ were tested for cell viability after exposure to Glusulase $(A)$, ether $(B)$ and $55.5^{\circ} \mathrm{C}(C)$ for the indicated times (see Materials and methods). The efficiency of ascus formation in the sporulated cultures was $>80 \%$. 


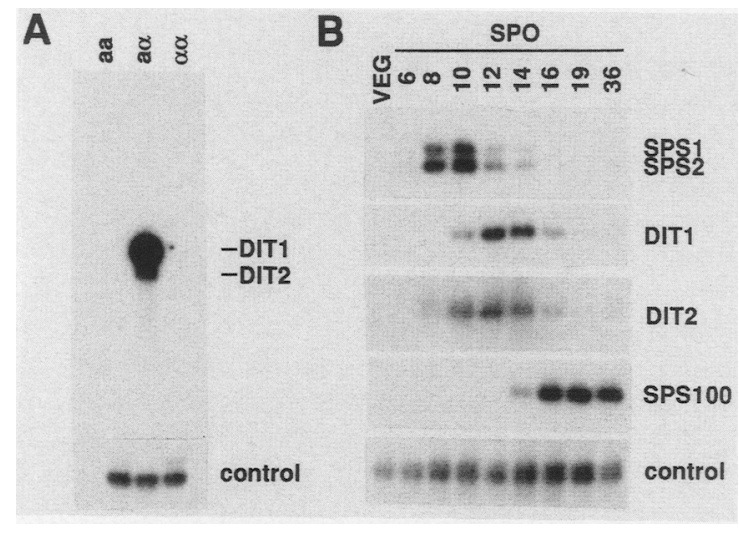

Figure 6. Developmental-specific expression of the DIT1 and $D I T 2$ genes. $(A)$ The DIT1 and DIT2 genes are not expressed in asporogenous MATa/MATa and MAT $\alpha / M A T \alpha$ cells in sporulation medium. Poly(A) ${ }^{+}$RNA purified from MATa/MATa, $M A T \mathbf{a} / M A T \alpha$, and $M A T \alpha / M A T \alpha$ cells at $12 \mathrm{hr}$ after transfer to sporulation medium was separated by electrophoresis through an agarose gel and transferred to a nylon membrane. The RNA blot was hybridized with a radiolabeled pEMBL19 derivative containing the yeast DNA insert of pPB-10 (Fig. 3A). The control transcript represents hybridization with radioactively labeled pC4 (Law and Segall 1988). (B) The DIT genes define a temporally distinct class of sporulation-specific genes. Poly(A) ${ }^{+}$ RNA purified from MATa/MAT $\alpha$ cells growing vegetatively (VEG) and from cells at the indicated times after transfer to sporulation medium (SPO) was separated on an agarose gel and transferred to a nylon membrane. The blots were hybridized with radioactively labeled probes containing the SPS1 and SPS2 genes (p18; Percival-Smith and Segall 1986), the DIT1 gene (a pEMBL19 derivative containing the yeast DNA insert of pPB-13), the DIT2 gene (a pEMBL19 derivative containing the yeast DNA insert of pPB-12), the SPS100 gene (pE18-B8a; Law and Segall 1988), and a control gene (pC4). Only the portions of the blots hybridizing with the probes are shown. $(C)$ The DIT genes are expressed at the time of prospore enclosure and just prior to the time of dityrosine accumulation. MATa/MATa cells were examined at various times after transfer to sporulation medium. Appearance of immature $(O)$ and mature asci ( $\square$ ) was monitored by light microscopy with phase-contrast optics. Poly $(\mathrm{A})^{+}$RNA was purified from aliquots of cells, and a blot was probed for DIT2 transcripts as described above. The relative level of DIT2 transcripts (O) was determined by densitometric scanning of an autoradiograph of the blot. Acid hydrolysates of aliquots of cells were analyzed by thin layer chromatography, and relative levels of dityrosine ( $\square$ ) were determined by densitometric scanning of a photograph of the chromatogram taken under UV illumination.

rated by 899 nucleotides. A potential TATA box consensus sequence is found 114 and 107 nucleotides upstream of the translational start codons of the DIT1 gene and the DIT2 gene, respectively. We then mapped the transcriptional start sites by primer extension. The 5' ends of DIT1 transcripts mapped to multiple sites 18-50 nucleotides upstream of the translational start codon; the $5^{\prime}$ ends of DIT2 transcripts mapped to sites 22 and 31 nucleotides upstream of the translational start codon.

The ORF corresponding to DIT1 encodes an acidic $61.3-\mathrm{kD}$ protein. The ORF corresponding to DIT2 encodes a $56-\mathrm{kD}$ protein with a hydrophobic amino terminus. We note that neither of the predicted proteins has a high content of tyrosine. This makes it unlikely that either of the DIT genes encodes the putative precursor to the dityrosine-containing macromolecule of the spore wall.

\section{DIT2 is a member of the cytochrome P-450 superfamily}

Comparison of the deduced amino acid sequences of DIT1 and DIT2 with the NBRF/PIR and SWISS-PROT data bases revealed that the DIT2 gene product had significant homology with several members of the cytochrome P-450 superfamily. The highest homology noted for the predicted DIT2 gene product was $24 \%$ identity with the bovine cytochrome P-450 XVIIAl (17 $\alpha$-hydroxylase/17,20 lyase; Zuber et al. 1986). Identity with the rat cytochrome P-450 IIIAl [pregnenolone $16 \alpha$-carbonitrile-inducible (pcn1); Gonzalez et al. 1985], rat P-450 IIIA2 [(pcn2); Gonzalez et al. 1986], and human P-450 XIA] [cholesterol side-chain cleavage (scc); Chung et al. 1986] was $\sim 20 \%$, whereas identity with the only previous known cytochrome $\mathrm{P}-450$ of $S$. cerevisiae (P-450 LI, lanosterol 14 $\alpha$-demethylase; Kalb et al. 1987) was only $12 \%$.

Analysis of $>70$ cytochrome P-450s led to the grouping of these proteins into 15 distinct families $/ \mathrm{Ne}$ bert et al. 1989). Although the sequence homology between families is low, Kalb and Loper (1988) identified a region of $\sim 170$ amino acids conserved among all cytochromes. This region, present in the carboxy-terminal portion of the proteins, is divided into four domains of sequence similarity that are separated by short stretches of variable length. The consensus sequence derived for this region, which includes invariant, conserved, and variable amino acids, is presented in Figure 8 . The high degree of identity observed between this sequence and the carboxy-terminal domain of the DIT2 gene product $(53 \%)$ confirmed that DIT2 is indeed a member of the cytochrome P-450 superfamily (Fig. 8). The highest percentage of invariant residues among the P-450s occurs in the proximal cysteine-containing heme-binding region. The invariant cysteine of this domain, as well as several neighboring invariant residues, is present in the DIT2 gene product (Phe-428, Cys-435, Gly-431, Gly-437). Although the invariant threonine residue of the distal heme-binding region, as well as the adjacent serine/threonine-rich region, is not found in the DIT2 gene product, several other conserved amino acids of this region, in particular an invariant glycine (Gly-294), are present in $D I T 2$. We propose that the DIT2 gene defines a novel cytochrome P-450 that could be involved in cross- 
$-465$

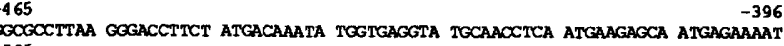
-395
TTAAGGGGTA AGTAACCATC CGAATTTGTT GTTTCCTAAC AATTTGTCTA ATTTACTCAA TAATATCAGG -325
AGAATTEATC GAAAAAACCA AACCAGCAAC COCTCACAAA TAAGGGAACA TAAAGTAAT GCTOCTCTTT -255 ACATACATEG CACTCAATCC CAGACGTCGC GTGCTAAAAA TCCTTATATT ATIGGCOCCT CACGAGTTTA
-185

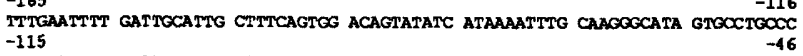
-115

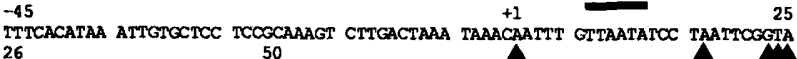
26 AACCTITGTC GAGACATTAA CAAAA

51/1 110/20 ATG ACA TTT ACT ACC AAC TTG COC TCA ACC TOC GAG CAG TCA ATA TCA OCA CCT OCC TCT mat-thr-phe-thr-ser-asn-leu-pro-ser-ser-ser-glu-gln-ser-110-ser-pro-pro-ala-ser TCA ITT TCT TCA TCG ACT GAT ACG TTG AAA GAT ATT GAT ATT COC CAT AAT GGG GCC GAT sar-phe-ser-ser-ser-thr-asp-thr-leu-1ys-asp-1le-asp-1le-pro-h1s-asn-gly-ala-asp171/41 TCT ACA TAT AGT AAA TTT CTG GCC CTG TAT TOC AGA AGC GAC AAA TGT GAC $230 / 60$ lou-sor-thr-tyr-sor-1ys-phe-lou-ala-leu-tyr-cys-arg-ser-asp-lys-cys-asp-asp-phe$290 / 80$
TAC TCT TTA GAG GAA AAA CAG AAT TCT AAA TTT GGA GAC CAA TGG CTC CAC TTT ATC AAC tyr-sor-lou-glu-glu-1ys-gln-asn-cys-1ys-pho-gly-asp-gln-trp-leu-asp-phe-1le-asn291/81
ACT ACT ATT CAC AAT CTG GAC TTT TCT GAA TCC GAA GTA AGT OGA COG GTT TCT GAA AGA ATT 351/101
TMG CCA GCT TCT TTA GCA AAT AAA TTT ACC AAT AAT TTG CCA GCT TCT TTA GCA AAT AAA TTT ACC AAT AAT TTA GGA GTG QCA ATA AAG ATT TCT lou-pro-ala-ser-lou-ala-asn-1 ys-pho-thr-asn-asn-lou-gly-val-al a-1le-1ys-1le-ser-
411/121 GAA TAT ACA COC GAT GAC GAA Cœ CAG ATT CGT GOG TGT GTT ACA ACA GTT GAG AAT GAA glu-tyr-thr-arg-asp-asp-giu-arg-gln-1lo-a ag-gly-cys-val-thr-thr-val-glu-asn-glu471/241 TCT TTC AAT AAC TGG TTC GTA TAT CAT ATT TTA GAC CAA TCT CAA TTA TCT CTA AGT asn-ser-phe-asn-asn-t rp-phe-val-tyr-his-1 le-leu-asp-gln-ser-gln-leu-ser-leu-ser 531/161
590/180 GAA CAT CCA ATT GTA ACC AAA GAA GTT AAG TAT CAC GAA TTA TTT GCA GAT TTT TTT GAG glu-his-pro-1le-val-thr-lys-glu-val-lys-tyr-h1s-glu-leu-phe-ala-asp-pho-phe-gluA91/181 AAT TTG AAA AAC ACA ATA GTT AAT GAT CAA T@G AAT TTT $O G T$ OGC OGT GAT TAT TTY AAA AAT TTE AAA AAC ACA ATA GTT AAT GAT CAA TCG AAT TTT CGT OGC CGT GAT TAT TTT
lys-asn-lou-1ys-asn-thr-1lo-val-asn-asp-gln-trp-asn-pho-gly-gly-arg-asp-tyr-pho$651 / 201$
ATT GAA CGT TCA AGA TAT TTT ACC GAT CGA TAT TTG AGA ATT GAA TGC ATC ITG
$710 / 220$
QCG ATT GAA CGT TCA AGA TAT TTT ACC GAT CGA TAT TTG AGA ATT GAA TGC ATC TTG OCA QCG
$110-$ glu-ang-ser-a 2 -ty 7I1/221 CCA TGT AAG TCA TCT AAT GAG CAA AAA GTG TAC GGT TCC GIT CCT GAC AAA OCC GAA phe-pro-cys-1ys-ser-ser-asn-glu-gln-1ys-val-tyr-gly-ser-val-pro-asp-lys-gly-gluGAA CTC GCT TTG AAA AGA TTA ATA AAA GOC ACA CAA GAC CTT GTC AAG ATA TAT OCA CCG glu-lou-ala-lou-1ys-arg-10u-1 la-1ys-ala-thr-gln-a sp-10u-val-1ys-1lo-tyr-pro-proGGT ATG AAA ATT TGG ATA GTT AGT GAT GQC CAT GTT TTC TCC GAT TGT ATT QGG GTC GAT gly-met-1ys-11e-trp-1le-val-ser-asp-gly-h1s-val-phe-ser-asp-cys-110-gly-val-aspGAT GAC GTC GTG AGT ACT TAC ACG ACC AAA TTG CAC GAA CTG TAT AAA AGA GTG 95T ATA asp-asp-val-val-sor-thr-tyr-thr-thr-1ys-lou-h1s-glu-lou-tyr-1ys-arg-val-ala-1le951/301 GTT GAC GOC ATT GOC TTT TGT GGA TTG AAC GAT TTA TTT TTT AGC $1010 / 320$ pro-gly-val-asp-ala-1 le-gly-pho-cys-gly-leu-asn-asp-leu-phe-phe-ser-gly-ala-alaAGT AAM GTT TTC GAT CCA AAG TOG GTT AGT GAT GTT GAA GTT GCA CAC TAC ACA GGA 340 ser-lys-val-phe-asp-pro-Iys-t rp-val-ser-asp-val-glu-val-ala-h1s-tyr-thr-gly-thr-
$1071 / 341$ CAA ATC TGT CCT AAG TCC GAT TTG TCG AGA CAG ATT TTG ATG AAA QGC TGT GAT ACA GAT gln-1 le-cys-pro-lys-ser-a sp-leu-ser-arg-gin-1lo-leu-mot-lys-gly-cys-asp-thr-aspOCA GGT CGT TTS AGA AAG CAG ATT GCA ATA GAA GCA CAT OCA AGA TTG CAT CTG TAT AGG ala-gly-arg-1 ou-arg-lys-gln-1 lo-ala-1lo-glu-gly-his-pro-arg-lou-his-lou-tyr-arg-
$1191 / 381$ GXC TTT TCA CGT TTT ATG ATG GAA GAT TTA TCT CTA CTG GAA CAT TTC CAA AGT TAT TCC gly-phe-ser-arg-pho-met-mot-glu-asp-leu-ser-leu-leu-glu-his-pho-gln-sar-tyr-ser-
$1251 / 401$
$1310 / 420$

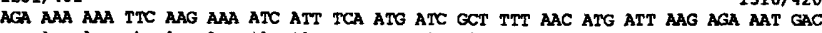
axg-1ys-1ys-phe-1ys-1ys-110-11e-ser-met-110-ala-phe-asn-met-11e-1ys-arg-asn-asp$1311 / 421$
OOG TAT TOS AAC TTA GTG GAA TTG ATA TTC CCT CAT CAT TTG AGA ATT TCT ATT CAT
$1370 / 440$ ala-tyr-ser-asn-leu-val-glu-1eu-1 le-phe-pro-h1s-h1s-1eu-arg-1le-ser-110-h1s-ala$1371 / 441$ $1430 / 460$ CAC ACT AAC AGC GOG COC AAA TTT GGT ATA AAA GTA ATC TCC AAC GAA CAG TGT TCT ATT hls-thr-asn-ser-gly-pto-lys-pho-gly-1le-lys-val-1le-ser-asn-glu-gln-cys-ser-1le-
$1431 / 461$
$1490 / 480$ $1490 / 480$
GTT AGT TOG TTA GAA GAC CTT GAT GAA COC AAA TTT GAA GAT TTT TTA CAT ATT CCC ACA
val-ser-ser-leu-glu-asp-1eu-asp-glu-pro-1ys-phe-glu-a sp-pho-leu-his-11e-pro-thr val-ser-ser-leu-glu-asp-leu-a sp-glu-pro-lys-phe-glu-a sp-pho-leu-his-11e-pro-thr
$1491 / 481$
$1550 / 500$ OCT TGG CAT AAT TGT GTC GTS AAG GTT GAG GAT GAA AAG GAG AAA TAC TTT TTG ACA AAA pro-t tro-h1s-asn-cys-val-val-1ys-val-glu-asp-glu-lys-glu-lys-tyr-phe-leu-thr-lys TCA AAA GTA GTC AAG GAG CCT CTC GAA AAG GST ATG TAT GAT GGT GTA TEG AAA GAT ACT sor-Iyg-val-val-1ys-glu-ala-lou-glu-1 ys-gly-mat-tyr-asp-gly-val-trp-lys-asp-thr1611/521 CGT TTC GAT ATT GGA GAA GGA GGA CAT TTC GTT ATC AAG AAA ATC TCT TAA
arg-pho-asp-110-gly-glu-gly-gly-h1s-phe-val-11e-1ys-1ys-1le-ser-sTOP 1662 TAAAGTAGA GCCCTACATT GGTCTACCTT TTTGTTCTTT TACTTAAACA TTAGTTAGTT CGTTTICTTI

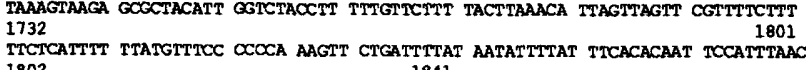
1802
AGAGGGGAAT AGATTCTTTA $O$ CTTAGAAAA TTACTGATCC
$-367 \quad-298$ -297
$-260 C T T T T$ TATTTTTTCT IGOCAAGAGA ACCCTITTAT TTATEGCCAG ACOCOCGTCG CAAAAAAAGG
-228 -297 -227
OCAATACOT ATTOCACCCC ICATTACTIC COCGATACAA TTTATTTTCA CTTCTTTCGA TGAATGCAGT

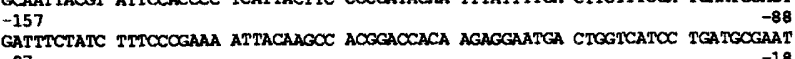

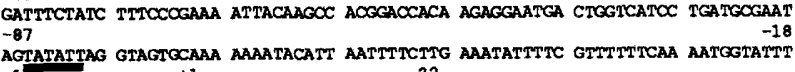

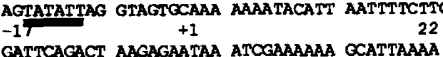
GATTCAGACT AAGAGAA $\triangle$ 23/1
ATG GAG TTG TTA AAG CTT CTG TGT TTG ATT TTA TTT CTT ACT CTT TCC TAT GTC @CC TTT mat-glu-leu-leu-1ys-leu-leu-cys-leu-1 le-leu-pho-leu-thr-leu-ser-tyr-val-ala-pho83/21 2 TT GTC CCA CCT CTA AAC TTTT COC AAA AAT ATA COC ACC ATC CCA TTT TAT GTA ala-1lo-1le-val-pro-pro-1eu-asn-pho-pro-1ys-asn-1le-pro-thr-1lo-pro-pho-tyr-val143/41
$202 / 60$ val-phe-leu-pro-val-1le-pho-pro-1le-asp-gln-thr-glu-leu-tyr-asp-leu-tyr-1le-argval-phe-leu-pro-val-1le-pho-pro-1 le-asp-gln-thr-glu-leu-tyr-asp-leu-tyr-11e-arg
203/61 203/61 2 ATA ATG GAA AAA TAC GGT GCT GTA AAA TTT TTC TTT GGT TCA CGG TGG AAT ATT CTC glu-sor-mot-glu-lys-tyr-gly-ala-val-1ys-phe-phe-pho-gly-ser-arg-trp-asn-1le-leu263/81
vat
$322 / 100$ GTT TCT OCT TCT GAG TAT CTA GCA CAA ATA TTC AAA GAT GAA GAT ACT TTT OCG AAG AGC val-ser-arg-ser-glu-tyr-leu-ala-gln-1le-phe-1ys-asp-glu-asp-thr-phe-al a- 1 ys-ser
$382 / 120$ gGt aAT CAA Aag AAA ATC CCA TAC AGT GCT CTT GCC GCT TAC ACA GOG GAC AAT GTC ATT gly-ast-gln-1ys-1ys-110-pro-tyr-ser-ala-10u-ala-ala-tyr-thr-gly-asp-asn-val-1le-
$383 / 121$
442/140 383/121 ser-ala-tyr-gly-ala-val-trp-arg-asn-tyr-arg-asn-ala-val-thr-asn-gly-lou-gln-his 443/141 502/160 TTT GAC GAT GCA CCT ATA TTC AAA AAT GCA AAA ATT TTA TGC ACT TTG ATA AAA AAC AGA phe-asp-asp-ala-pro-11e-phe-1ys-asn-ala-1ys-1le-leu-cys-thr-leu-1le-1ys-asn-arg-
$562 / 180$ 503/161 CTA GAA GCA CAA ACT TOG ATC CCT ATG GCA CCT TTA TOC CAG AGA ATG OCA TTG GAT lou-lou-glu-gly-gln-thr-ser-1 le-pro-met-gly-pro-leu-ser-gln-arg-met-ala-leu-asp 563/181 622/200 AAC ATT TCA CAG GTT GCS CTT GGA TTT GAT TTT GGT GCT CTA ACA CAT GAA AAA AAT GCT asn-1le-ser-gln-val-ala-leu-gly-phe-asp-phe-gly-ala-leu-thr-his-glu-lys-asn-ala 623/201 682/220 TTC CAC GAG CAT TTG ATT CGT ATT AAA AAG CAA ATA TTT CAT CCA TTC TTT TTA ACT TTT phe-h1s-glu-h1s-1eu-110-arg-110-1ys-1ys-gln-11e-pho-h1s-pro-phe-phe-leu-thr-phe 983/221 742/240 OCA TTC CTT GAT GTT CTT CCT ATT CCT TCA AGA AAA AAA GCC TTC AAG GAT GTT GTT AGT pro-pho-lou-asp-val-lou-pro-1lo-pro-sor-ang-lys-lys-ala-pho-lys-asp-val-val-ser
743/241 743/241 GGA GA CTT CTC GTT AAA AGA GTT CAA GAT GAA TTA GTC AAT AAT TAC AAA TTT GAA TTT AGA GAA CTT CTC GTT AAA AGA GTT CAA GAT GAA TTA GTC AAT AAT TAC AAA TTT GAA
phe-arg-gIu-leu-leu-val-iys-arg-val-gln-asp-glu-leu-val-asn-asn-tyr-lys-phe-glu803/261 ACT TTPT GCT GOC AGT GAT CTA ATP CGT GCT CAC AAT AAC GAA ATA ATC GAC TRC Gin-thr-thr-pho ala ala 863/281 AA3 CAG TTG ACC GAT AAT ATC GTC ATT ATC CTT GTC GCT GOC CAT GAA AAC $\triangle$ CCG CAG TTG lys-gln-leu-thr-asp-asn-1le-val-1le-1le-leu-val-ala-gly-h1s-glu-asn-pro-gln-leu1ys-gln-leu-thr-asp-asn-1le-val-1le-1le-lev-val-ala-gly-h1 G-glu-asn-pro-gln-leu-
$982 / 320$ CTA TTT AAT AGT TCA CTC TAC CTT CTA GOC AAA TAT TCA AAT GAA TGG CAA GAG AAA CTC lou-pho-asn-ser-ser-lou-tyr-1 lu-1 ou-ala-lys-tyr-ser-asn-glu-trp-gln-glu-lys-leu983/321 1042/340 AGG AAG GAA GTA AAC GOC ATC ACT GAT CCA AAA GOC TTA GCA GAT TTA CCC TTA TTA AAT arg-lys-glu-val-asn-gly-1le-thr-asp-pro-lys-gly-leu-ala-asp-leu-pro-lou-leu-asn1043/341 $1102 / 360$ QCT TTT CTC TTC GAA GTA GTA AGA ATG TAT CCT CCT TTG AGC ACA ATT ATT AAT AGA TGT ala-phe-leu-pho-glu-val-val-arg-met-tyr-pro-pro-leu-ser-thr-1le-1le-asn-arg-cys$1162 / 380$
$1103 / 361$ thr-thr-lys-thr-cys-1ys-leu-gly-ala-glu-1 le-val-1le-pro-lys-gly-val-tyr-val-gly$1163 / 381.1222 / 400$ tyr-asn-asn-pho-gly-thr-ser-hls-asp-pro-lys-thr-trp-gly-thr-thr-al a-asp-asp-phe1282/420 AAA OCA GAA AGA TGG GGT TCA GAT ATC GAA ACC ATA AGG AAA AAC TOG AGA ATG OCG AAA lys-pro-glu-arg-t rp-gly-ser-asp-1le-glu-thr-1le-arg-lys-asn-trp-arg-mat-ala-lys-
$1342 / 440$ 1283/421 asn-arg-cys-ala-val-thr-gly-phe-h1s-qiy-gly-arg-arg-ala-cys-lou-gly-glu-lys-lou1343/441 1402/460 GCC CTA ACA GAA ATG AGA ATT TCT TTG GCT GAA ATG TTG AAA CAG TTT CGA TGG AGT CTT ala-leu-thr-glu-met-arg-1 le-ser-leu-ala-glu-met-leu-lys-gln-phe-arg-trp-ser-leu-
$1462 / 480$ $1403 / 461$
GAC $\varnothing$ T GAA TGG GAA GAA AAA TTA ACT COC $Q C T$ GOG CCT CTT TOC CCT CTT AAT TTA AAO GAC OCT GAA TGG GAA GAA AAA TTA ACT COC QCT GOG CCT CTT T\&C CCT CTT AAT TTA AAO asp-pro-glu-t $2 p-g l u-g l u-1$ ys-leu-thr-pro-
$1463 / 481$ $1492 / 489$
$1463 / 481$
ITA AAA TTT AAC GAG AAT ATA ATS CAA TAA lou-lys phe-asn-glu-asn- 1 le-met-glu-STOP 1493

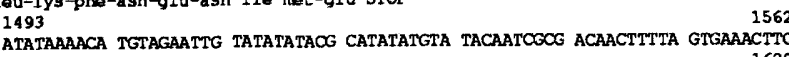
1563
ATA TTTGTATCCA GTGAAAATGA AAGGAACAGA ACCTGACCAA AGGTCAGTAG AAAAAAAAA AGCCTTTTAT 1633
AGAAGTCTT ATCCAATCGT IGACATTTTG TCTGCTCTAT TTAATGCTTC AAAAATCTGA TCCCAAAAGT 1772
1703
ACTOGATATT CAAATCGAGA CCAATTATTG TACCAACATC ACTGTCATTT GGATATTCTT TTTCAATGA 1773
AATTTTCOCT GAGTTTTCOT TGAAAACATC ATGCAGGATA TGTCCATTCT CTTGTAGCGA AATCCAACCG 1843.1898

Figure 7. (See following page for legend.) 


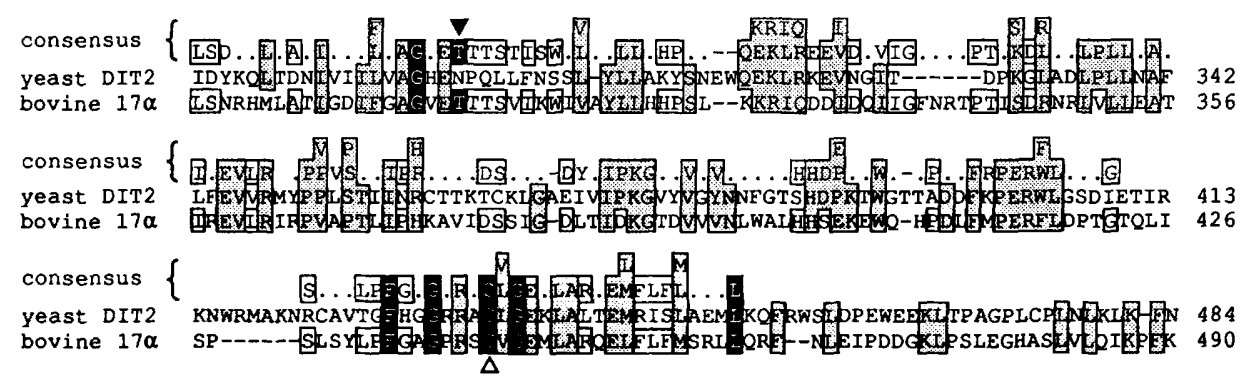

Figure 8. Comparison of the carboxy-terminal region of DIT2 with the corresponding region of the bovine cytochrome P-450 XVIIAl (17 $\alpha$-hydroxylase/17,20 lyase) and the cytochrome P-450 consensus. The sequence for P-450 XVIIAl (17 $\alpha$-hydroxylase/17,20 lyase) (Zuber et al. 1986) begins at amino acid 287. The sequence for DIT2 begins at amino acid 278 . The consensus sequence is from Kalb and Loper (1988). In those positions where the consensus sequence includes two or more amino acids, only the amino acids that are relevant for this comparison are included. Dots indicate that no consensus exists at a given position. Blanks in the consensus sequence denote regions of variable length that have no significant consensus (Kalb and Loper 1988). Gaps (-) were introduced for optimal alignment. Solid boxes indicate highly conserved amino acids directly or indirectly involved in heme binding (Poulos et al. 1985). ( $\triangle \mid$ The cysteine that provides the axial thiolate ligand for the heme iron atom; $(\nabla)$ the threonine residue, discussed in the text. Identical amino acids are boxed. The boxes are shaded when the identity includes the DIT2 gene product.

linking tyrosine residues (see Discussion). No significant homologies with other proteins were detected for DIT1.

\section{Discussion}

We made use of a haploid yeast strain that can complete sporulation successfully in conjunction with an assay for fluorescence of dityrosine in the spore wall to identify mutants with defects in spore wall maturation. In this study, we characterized two genes, DIT1 and DIT2, that contribute to the formation of the outermost layer of the spore wall. Mutation of either gene generated the same phenotype. The most obvious defects of strains containing dit 1 or dit2 alleles were the lack of dityrosine in the mutant spores and the sensitivity of the mutant spores to Glusulase. Electron microscopic examination of asci of mutant strains demonstrated that the thin and very osmiophilic surface layer of the spore wall was absent. The underlying more diffuse chitosan-containing layer was present, although this layer appeared to be fragmented in some instances. We presume that the outermost layer of the wall normally contributes to the stability of the spore wall and that the absence of this layer in the mutant strains led to more frequent fracturing of the spore walls during preparation of the cells for electron microscopy. The observation that the mutant spores could be readily stained with primulin, and the demonstration that the glucosamine content of mutant spores was similar to that of wild-type spores further confirmed the absence of any major defect in the formation of the chitosan-containing layer of the spore wall in these mutants. As the failure to form the outermost layer of the spore wall, as visualized by electron microscopy, correlated with a failure to synthesize the spore wall-specific dityrosine, we infer that the dityrosinecontaining macromolecule is present on the surface of the spore. This conclusion is supported by the ability to readily label purified spores with ${ }^{125}$ ( Briza et al. 1990).

Because our data indicate that dit103, dit104, and dit108 are alleles of DIT1, we rename them dit1-103, dit1-104, and dit1-108, respectively. Similarly, we rename dit102, dit106, and dit107 as dit2-102, dit2-106, and dit2-107, respectively. We note that because DIT1 and DIT2 are closely linked, both act in a spore-autonomous manner, and the phenotypes generated by mutations in either gene are indistinguishable, standard genetic allelism tests would most probably have failed to reveal the existence of two separate genes.

Expression of the DIT1 and DIT2 genes at the time of prospore enclosure could readily account for the sporeautonomous behavior of these genes. The lack of complementation between sister spores would result from synthesis of the DIT gene products within the maturing spore at a time when free exchange of macromolecules between spores is restricted. This suggestion of synthesis of spore wall components within the developing spore is consistent with the observation of Lynn and Magee (1970) that endoplasmic reticulum is found apposed to the prospore wall within the immature spore. Kurtz and Lindquist (1986) noted that some sporulationspecific transcripts that are synthesized during ascus formation and are presumed to encode spore wall proteins are selectively localized to the ascal cytoplasm. As genes encoding such transcripts would not be expected to behave in a spore autonomous manner, we presume

Figure 7. Nucleotide sequence of the nontranscribed strand of the DIT1 gene $(l e f t)$ and the DIT2 gene (right). Both sequences start at the NarI site present in the DIT1-DIT2 intergenic region (see Fig. 3). Translation of the predicted ORF is shown below the DNA sequence. The putative TATA boxes are underlined, and major transcription start sites are indicated with solid triangles. Throughout the ORF, the right-hand number refers to the position of the codon relative to the initiator ATG and the left-hand number refers to the position of the nucleotide relative to the start of transcription. Outside the ORF, the numbers refer to the position of the nucleotide. 
that the transcripts encoded by the DIT1 and DIT2 genes do not belong to this class of RNAs. On the other hand, transcripts encoded by the genes represented by dit 101 and dit105, which behave as recessive mutations, may belong to this class. Alternatively, the transcripts may accumulate prior to enclosure of the newly formed nuclei by the prospore wall, thereby allowing complementation between sister spores.

The spore autonomous behavior of the DIT2 gene, which we postulate encodes an enzyme involved in the cross-linking of tyrosine residues (see below), is somewhat surprising as it is unlikely that the cross-linking would occur within the prospore prior to deposition of the presumptive tyrosine-rich macromolecule on the spore surface. As the predicted DIT2 gene product has a hydrophobic amino-terminal domain, it is possible that the enzyme is present on the surface of the spore but remains membrane-bound such that its activity is restricted to the spore of origin. Most cytochrome P-450s are membrane-bound, being localized to the endoplasmic reticulum or mitochondria.

We presume that the protective nature of the spore wall derives both from the resistance of the highly cross-linked macromolecular network present on the surface of the spore to proteolytic digestion (Briza et al. $1990)$ and to the impermeable nature of this surface layer, as exemplified by exclusion of primulin and ether. Previous studies have indicated that treatment of purified spore walls with Glusulase leads to digestion of the inner glucan- and mannan-containing layers with both surface layers remaining intact (Briza et al. 1986). Our data now establish that it is the outermost layer of the spore wall that is responsible for the resistance of spores to Glusulase. The observation that the spore wall is also responsible for ether resistance supports the previous suggestion that the SPS100 gene encodes a protein involved in spore well maturation (Law and Segall 1988). It is unclear why the absence of the outermost layer of the spore wall would reduce the heat resistance of the spores. We speculate that a reduction in stability of the spore walls resulting from the absence of the crosslinked surface layer, as well as an increase in permeability of the spores, could lead indirectly to reduced heat resistance.

The correlation of expression of the DIT1 and DIT2 genes with dityrosine synthesis, as well as the fact that the homozygous mutants formed spores that were totally devoid of dityrosine, suggests that the DIT1 and DIT2 genes may be directly involved in dityrosine synthesis. The only known mechanism for the cross-linking of tyrosine residues is by a peroxidative reaction (Foerder and Shapiro 1977). Because DIT2 was found to have significant homology with members of the cytochrome P-450 superfamily, we propose that cross-linking of the tyrosine residues in the yeast spore walls occurs via a novel cytochrome P-450-catalyzed oxidation. The cytochrome P-450 family is a group of $>100$ heme-containing monooxygenases that act predominantly as hydroxylases on a large variety of substrates. The greatest homology among cytochrome P-450s is found within the region encompassing the two $\alpha$-helices involved in heme binding. DIT2 contains all of the highly conserved amino acids suggested to be directly involved in heme binding (Poulos et al. 1985). However, a threonine residue that is conserved in the distal heme-binding helix of all but one P-450 (Kalb and Loper 1988) is replaced by an asparagine residue in DIT2 (Asn-297) and is followed by a proline residue (Pro-298). The threonine residue plays a crucial role in P-450 activity, distorting the distal helix above the heme (Poulos et al. 1985) and contributing to substrate binding (Imai and Nakamura 1988) and probably to the scission of the oxygen-oxygen bond (Imai et al. 1989). Comparison of the secondary structures of DIT2, rat P-450pcn1, rat P-450pcn2, and human P-450scc, as predicted by the algorithm of Garnier et al. (1978), suggests that Pro-298 in DIT2 could serve a role similar to that of the conserved threonine residue in destabilizing the distal helix. The Asn-297 residue in DIT2 may reflect adaptation of the cytochrome to a novel enzymatic activity. Interestingly, P-450s with the highest overall homology to DIT2 have somewhat unusual activities. P-450scc and P-450 17 $\alpha$ hydroxylase/ 17,20 lyase have carbon-carbon bond cleavage activity in addition to hydroxylation activity (Ortiz de Montellano 1986), and P-450pcn1 and P-450pcn2 catalyze the dehydrogenation of 1,4-dihydropyridines. The suggested mechanisms of action for these P-450s can be readily adapted for dityrosine synthesis. Oxidation of 1,4-dihydropyridines involves radical formation at the heteroatom and subsequent rearrangement of covalent bonds leading to the formation of the final reaction products (Guengerich and Böcker 1988). A similar mechanism has been proposed for cholesterol side-chain cleavage by P-450scc (Ortiz de Montellano 1986). These studies indicate that P-450s can perform reactions of the type suggested by Gross and Sizer (1959) for the formation of dityrosine by a peroxidative reaction. Although, by definition, peroxidases do not use dioxygen directly, a cytochrome P-450 could produce the same phenoxy radical that is generated by a peroxidase. Ortiz de Montellano (1986) also suggested an alternative mechanism for the side-chain cleavage reaction of cholesterol that can also be easily adapted to dityrosine synthesis, which involves the addition of a hydroxyl group to the activated oxygen.

Consistent with the absence of the chitosan layer in spores of the strain containing the dit101 mutation, recent experiments have indicated that this strain lacks chitin synthase III (C. Bulawa, M. Pammer, and M. Breitenbach, unpubl.). Chitin is thought to be the precursor to the spore wall chitosan (Briza et al. 1988). We presume that the absence of the chitosan layer in spores of the strain containing the dit101 mutation and in spores of glucosamine auxotrophs (Ballou et al. 1977; Briza et al. 1988/ indirectly prevents the deposition of the outermost dityrosine-containing layer. These mutants accumulate a low level of dityrosine in their spores (Briza et al. 1990). We do not yet know the function of the DIT1 gene or the gene represented by the dit105 allele. Potential roles for Dit gene products include a reductase that acts with DIT2 in cross-linking tyrosine, a 
racemase involved in catalyzing the formation of the Dtyrosine present in the spore wall dityrosine, products involved in establishing putative intermolecular interactions between the chitosan layer and the surface layer of the spore wall, and a putative tyrosine-rich precursor to the dityrosine-containing macromolecule. As the dityrosine-containing macromolecule has properties similar to a bacterial peptidoglycan (Briza et al. 1990), it is also possible that a Dit gene encodes an enzyme responsible for the nonribosomal incorporation of tyrosine into a peptidic structure. It will be interesting to determine whether a soluble or spore surface-bound and tyrosinerich polypeptide accumulates in the $\mathrm{Dit}^{-}$mutants.

\section{Materials and methods \\ Strains and culture conditions}

The haploid meiosis strain PB2-1C (MAT $\alpha$ spo13-1 sir4ts trp1-1 leu2 his6) (Briza 1987) was used for the isolation of mutants. SHU32 (MATa leu2 trp1 ura3) was used to mate with strains containing the original dit alleles to obtain diploids for the initial electron microscopic analyses of heterozygotes (Fig. 2). The strains used for the construction of disruption alleles of DIT1 and DIT2 were W3031A-H (MATa can1-100 leu2-3,112 trp1-1 ura3-1 ade2-1) and W3031B-T (MATa can1-100 his3-11 leu2-3,112 ura3-1 ade2-1) (Law and Segall 1988). Cells were sporulated on plates containing $1 \%$ potassium acetate, $0.1 \%$ yeast extract, and $0.025 \%$ glucose after growth on YEPD plates ( $1 \%$ yeast extract, $2 \%$ peptone, $2 \%$ glucose) or in liquid medium ( $1 \%$ potassium acetate with appropriate supplements) after growth in YEPA medium $11 \%$ yeast extract, $2 \%$ peptone, $1 \%$ potassium acetate) as described (Law and Segall 1988). The sporulation temperature was $23^{\circ} \mathrm{C}$ for $\mathrm{PB} 2-1 \mathrm{C}$ and $30^{\circ} \mathrm{C}$ for all other strains. Ascus formation was monitored by light microscopy, using phase-contrast optics. The efficiency of sporulation of PB2-1C and the diploid strain LP-HT, obtained by mating W3031A-H and W3031B-T, was $\sim 25 \%$ and $70 \%$, respectively.

\section{Screen for spore wall mutants}

Cells of the strain PB2-1C mutagenized by exposure to ethyl methanesulfonate (EMS) (reducing viability to $6.5 \%$ ) or UV irradiation (reducing viability to $12.5 \%$ ) were plated on YEPD. After the survivors had grown up at $30^{\circ} \mathrm{C}$, colonies were patched onto YEPD plates and grown for 1 day at $30^{\circ} \mathrm{C}$. The colonies were replica-plated onto sporulation medium (master SPO plate) and onto nitrocellulose filters on YEPD plates. After 1 day of incubation at $30^{\circ} \mathrm{C}$, the nitrocellulose filters were transferred to sporulation medium and incubated for 3-4 days at $23^{\circ} \mathrm{C}$. The sporulated colonies were then examined for dityrosine fluorescence as follows. First, as visualization of the fluorescence of the dityrosine present in spore walls requires prior removal of the outer ascal sac, the colonies were treated with Glusulase by transferring each filter to a 9-cm petri dish containing a mixture of $200 \mu \mathrm{l}$ of $\mathrm{H}_{2} \mathrm{O}, 70 \mu \mathrm{l}$ of Glusulase, and 15 $\mu \mathrm{l}$ of $\beta$-mercaptoethanol. After $5 \mathrm{hr}$ at $30^{\circ} \mathrm{C}$, each filter was transferred to a dish containing $300 \mu \mathrm{l}$ of $30 \% \mathrm{NH}_{3}$. The $\mathrm{NH}_{3}$ solution provides the basic $\mathrm{pH}$ required for the fluorescence of dityrosine. The nitrocellulose filters were then exposed to UV light $(302 \mathrm{~nm})$ and photographed with Polaroid 667 film and a blue filter (Kodak Wratten filter, $390-450 \mathrm{~nm}$ ) to obtain a record of nonfluorescent colonies. Approximately $10-15 \%$ of the colonies were nonfluorescent. The appropriate colonies on the master SPO plates were then examined microscopically by using phase-contrast optics to determine which of the nonfluorescent mutants had formed spores. Most of the nonfluorescent colonies were asporogenous. Acid hydrolysates of those mutants that appeared to form nonfluorescent spores were then analyzed by thin layer chromatography to qualitatively assess the amount of dityrosine. If no dityrosine was detected despite ascus formation, colonies were resporulated and the dityrosine content was measured by fluorescence spectroscopy of HPLCpurified material (see below). In this way, seven mutant strains (containing the mutations denoted dit101-dit105, dit107, and dit108) that formed dityrosine-deficient ascospores were obtained on examination of $10^{4}$ EMS-treated cells. Each of these mutants was derived from an independently mutagenized pool of cells. One putative spore wall mutant (containing the mutation denoted dit106) was obtained on examination of $3 \times 10^{3}$ UV-treated cells.

\section{Determination of dityrosine}

Detection of dityrosine by thin layer chromatography and HPLC was as described (Briza et al. 1986). To quantitate the amount of dityrosine, $10^{7}$ cells of a sporulated culture were subjected to acid hydrolysis. These cells had not been treated with Glusulase. The hydrolysate was subjected to HPLC fractionation (Polygosil $\mathrm{C}_{18}$ column, acetonitrile gradient in $0.01 \mathrm{M}$ trifluoroacetic acid), and the fractions presumed to contain dityrosine were analyzed by fluorescence spectrophotometry as follows. After dilution of the samples 1: 1 with $30 \%$ ammonia, fluorescence excitation spectra were recorded on a Hitachi F-3000 fluorescence spectrophotometer. The emission wavelength was $420 \mathrm{~nm}$, and the excitation wavelength was from 270 to $370 \mathrm{~nm}$. The spectra identified dityrosine-containing fractions and allowed quantitation of the amount of dityrosine. The putative dityrosine-containing fractions in the HPLC-derived fractions of the hydrolysates of mutant cells were identified by comparison with the elution position of dityrosine in the hydrolysate of wild-type cells.

\section{Cloning DIT genes by complementation}

Strains containing the dit102, dit103, dit104, or dit106 alleles were transformed with a yeast DNA library, consisting of a partial Sau3A digest of genomic DNA cloned in YEp13, constructed by Nasmyth and Tatchell (1980). Transformation of spheroplasts generated by Glusulase treatment was as described by Sherman et al. (1986). After the transformants had grown up on regeneration plates, the cells from $\sim 3000$ colonies were pooled and sporulated on plates as a lawn. After sporulation, cells were recovered from the plate and incubated at $30^{\circ} \mathrm{C}$ for 12 $\mathrm{hr}$ in $5 \mathrm{ml} 0.1 \mathrm{M}$ sodium phosphate $(\mathrm{pH} 5)$ containing $50 \mu \mathrm{l}$ Glusulase and $20 \mu l \beta$-mercaptoethanol. This step leads to lysis of most vegetative cells and spores of the Dit ${ }^{-}$mutants. Survivors were then grown up on selective medium, sporulated, and tested for dityrosine fluorescence, as outlined above in the mutant screening procedure.

\section{Nucleic acid procedures}

RNA was purified from yeast cells, and Northern analyses were performed as described (Percival-Smith and Segall 1984). Standard DNA manipulations were carried out by procedures described previously (Maniatis et al. 1982). Genomic and plasmid DNAs were isolated from yeast according to Sherman et al. (1986). Yeast DNA fragments to be tested for complementation were subcloned in YEpl3. For sequencing, various restriction 
fragments from the 6-kb yeast DNA insert of pPB-10 were cloned into pEMBL18 and PEMBL19. Unidirectional overlapping deletions were generated by using exonuclease III and S1 nuclease (Henikoff 1984). The sequence of both strands of the DIT1-DIT2 region was determined by the method of Sanger et al. (1977) with Sequenase (U.S. Biochemical Corp.). We compared the deduced amino acid sequences of DIT1 and DIT2 with the NBRF/PIR and SWISS-PROT data bases, using the FASTA program of Pearson and Lipman (1988) and the BIONET network (National Institutes of Health grant P41RR01685).

The one-step gene-disruption procedure of Rothstein (1983) was used to introduce mutations into the DIT1 and DIT2 genes as follows. First, the yeast DNA inserts of pPB-13 and pPB-12 (Fig. 3A) were subcloned into pEMBL19, generating pPB-15E and $\mathrm{pPB}-22 \mathrm{E}$, respectively. A $1.2 \mathrm{-kb}$ HindIII fragment containing the URA3 gene was isolated; after the ends had been filled in with DNA polymerase I, the fragment was cloned into the Ball site present within the coding region of the DIT1 gene present in pPB-15E, generating pPB-43E. pPB-43E DNA digested with MluI and HindIII was used to transform the yeast strains W3031A-H and W3031B-T to Ura ${ }^{+}$. The URA3 gene was similarly cloned into the BalI site present in the coding region of the DIT2 gene, which was present in pPB-22E, generating pPB-42E. pPB-42E DNA digested with HindIII and EcoRI was used to transform W3031A-H and W3031B-T. The appropriate MATa and MAT $\alpha$ strains containing the dit1:: URA3 alleles or dit2 :: URA3 alleles were mated to obtain homozygous mutant diploid strains.

The $5^{\prime}$ ends of the DIT1 and DIT2 transcripts were determined by primer extension, using the protocol described by Fouser and Friesen (1986). RNA isolated from MATa/MAT $\alpha$ cells at $12 \mathrm{hr}$ after transfer to sporulation medium was hybridized with synthetic oligonucleotides corresponding to +93 to +117 of the DIT1 sequence and to +168 to +191 of the DIT2 sequence (Fig. 7). The extended primers were run on sequencing gels alongside dideoxy chain-termination sequencing reactions that had been performed using the same primers hybridized to the appropriate DNA fragment.

\section{Electron microscopy and primulin staining}

Cells were prepared for electron microscopic examination by fixation and staining with glutaraldehyde, osmium tetroxide, and uranyl acetate as described in Briza et al. (1988). These procedures were optimized to allow visualization of the multilayered spore walls. Cells were treated with primulin and examined by fluorescence microscopy as described (Briza et al. 1988).

\section{Assays for resistance of spores to Glusulase, ether, and heat}

Resistance was determined for stationary phase cells that had been in YEPD medium for $36 \mathrm{hr}$ and for cells $72 \mathrm{hr}$ after transfer to sporulation medium. Glusulase resistance was assessed by resuspension of cells in undiluted Glusulase (Sigma type H-2) at room temperature in a hemocytometer chamber and monitoring of cell lysis by light microscopic examination. The number of surviving asci and spores was counted at various times. Resistance of cells to diethyl ether was assessed as described in Law and Segall (1988). To determine heat resistance, cell cultures were kept at $4^{\circ} \mathrm{C}$ for $12 \mathrm{hr}$ and diluted to a density of $3 \times 10^{6} \mathrm{cells} / \mathrm{ml}$ water. One milliliter of the cell suspension was added to an Eppendorf tube, which was then immersed in a $55.5^{\circ} \mathrm{C}$ circulating water bath. At various times, aliquots were taken and plated on YEPD plates.

\section{Acknowledgments}

We thank Joanne Chan and Max Blum for their help with the computer analyses, Jose Baptista for preparing synthetic oligodeoxynucleotides, John Loper for helpful discussions, and Breck Byers, Kim Nasmyth, and Paul Sadowski for valuable comments on the manuscript. This work was supported by a Medical Research Council (Canada) grant (MA-6826) to J.S., by the Austrian "Fonds zur Förderung der Wissenschaftlichen Forschung" project S29/03 to M.B., and by an EMBO long-term fellowship to P.B.

The publication costs of this article were defrayed in part by payment of page charges. This article must therefore be hereby marked "advertisement" in accordance with 18 USC section 1734 solely to indicate this fact.

\section{Note added in proof}

Sequence data described in this paper have been submitted to the EMBL Data Library. The P450 Gene Nomenclature Committee has proposed that CYP56 be the official designation for DIT2.

\section{References}

Andersen, S.O. 1964. The cross-links in resilin identified as dityrosine and trityrosine. Biochim. Biophys. Acta 93: 213215.

Atcheson, C.L., B. DiDomenico, S. Frackman, R.E. Esposito, and R.T. Elder. 1987. Isolation, DNA sequence, and regulation of a meiosis-specific eukaryotic recombination gene. Proc. Natl. Acad. Sci. 84: 8035-8039.

Ballou, C.E., S.K. Maitra, J.W. Walker, and W.L. Whelan. 1977. Developmental defects associated with glucosamine auxotrophy in Saccharomyces cerevisiae. Proc. Natl. Acad. Sci. 74: 4351-4355.

Briza, P. 1987. Ph.D. thesis, University of Vienna, Austria.

Briza, P., A. Ellinger, G. Winkler, and M. Breitenbach. 1988. Chemical composition of the yeast ascospore wall. The second outer layer consists of chitosan. J. Biol. Chem. 263: $11569-11574$

1990. Characterization of a D,L-dityrosine-containing macromolecule from yeast ascospore walls. $J$. Biol. Chem. 265: $15118-15123$.

Briza, P., G. Winkler, H. Kalchhauser, and M. Breitenbach. 1986. Dityrosine is a prominent component of the yeast ascospore wall. A proof of its structure. I. Biol. Chem. 261: $4288-4294$.

Byers, B. 1981. Cytology of the yeast life cycle. In The molecular biology of the yeast Saccharomyces cerevisiae: Life cycle and inheritance led. J.N. Strathern, E.W. Jones, and J.R. Broach), pp. 59-96. Cold Spring Harbor Laboratory, Cold Spring Harbor, New York.

Chung, B.-C., K.J. Matteson, R. Voutilainen, T.K. Mohandas, and W.L. Miller. 1986. Human cholesterol side-chain cleavage enzyme, P-450scc: cDNA cloning, assignment of the gene to chromosome 15, and expression in the placenta. Proc. Nat1. Acad. Sci. 83: 8962-8966.

Clancy, M.J., B. Buten-Magee, D.J. Straight, A.L. Kennedy, R.M Partridge, and P.T. Magee. 1983. Isolation of genes expressed preferentially during sporulation in the yeast Saccharomyces cerevisiae. Proc. Natl. Acad. Sci. 80: 3000-3004.

Dawes, I.W. 1983. Genetic control and gene expression during meiosis and sporulation in Saccharomyces cerevisiae. In Yeast genetics (ed. J.F.T. Spencer, D.M. Spencer, and A.W.R. Smith), pp. 29-64. Springer-Verlag, New York.

Dawes, I.W. and I.D. Hardie. 1974. Selective killing of vegetative cells in sporulated yeast cultures by exposure to diethyl 
ether. Mol. Gen. Genet. 131: 281-289.

Esposito, R.E. and S. Klapholz. 1981. Meiosis and ascospore development. In The molecular biology of the yeast Saccharomyces cerevisiae: Life cycle and inheritance (ed. J.N. Strathern, E.W. Jones, and J.R. Broach), pp. 211-287. Cold Spring Harbor Laboratory, Cold Spring Harbor, New York.

Foerder, C.A. and B.M. Shapiro. 1977. Release of ovoperoxidase from sea urchin eggs hardens the fertilization membrane with tyrosine cross-links. Proc. Natl. Acad. Sci. 74: 42144218.

Fouser, L.A. and J.D. Friesen. 1986. Mutations in a yeast intron demonstrate the importance of specific conserved nucleotides for the two stages of nuclear mRNA splicing. Cell 45: $81-93$.

Garnier, J., D.J. Osguthorpe, and B. Robson. 1978. Analysis of the accuracy and implication of simple methods for predicting the secondary structure of globular proteins. $/$. Mol. Biol. 120: $97-120$.

Gonzalez, F.J., B.-J. Song, and J.P. Hardwick. 1986. Pregnenolone $16 \alpha$-carbonitrile-inducible P-450 gene family: Gene conversion and differential regulation. Mol. Cell. Biol. 6: $2969-2976$.

Gonzalez, F.J., D.W. Nebert, J.P. Hardwick, and C.B. Kasper. 1985. Complete cDNA and protein sequence of a pregnenolone $16 \alpha$-carbonitrile-induced cytochrome P-450. A representative of a new gene family. I. Biol. Chem. 260: 74357441.

Gottlin-Ninfa, E. and D.B. Kaback. 1986. Isolation and functional analysis of sporulation-induced transcribed sequences from Saccharomyces cerevisiae. Mol. Cell. Biol. 6: 21852197.

Gross, A.J. and I.W. Sizer. 1959. The oxidation of thyramine, tyrosine and related compounds by peroxidase. $/$. Biol. Chem. 234: 1611-1614.

Guengerich, F.P. and R.H. Böcker. 1988. Cytochrome P-450-catalyzed dehydrogenation of 1,4-dihydropyridines. I. Biol. Chem. 263: 8168-8175.

Henikoff, S. 1984. Unidirectional digestion with exonuclease III creates targeted breakpoints for DNA sequencing. Gene 28: $351-359$.

Herskowitz, I. and Y. Oshima. 1981. Control of cell type in Saccharomyces cerevisiae: Mating type and mating-type interconversion. In The molecular biology of the yeast Saccharomyces cerevisiae: Life cycle and inheritance led. J.N. Strathern, E.W. Jones, and J.R. Broach), pp. 181-209. Cold Spring Harbor Laboratory, Cold Spring Harbor, New York.

Holaway, B.L., D.J. Lehman, D.A. Primerano, P.T. Magee, and M.J. Clancy. 1985. Sporulation regulated genes of Saccharomyces cerevisiae. Curr. Genet. 10: 163-169.

Hollingsworth, N.M. and B. Byers. 1989. HOP1: A yeast meiotic pairing gene. Genetics 121: 445-462.

Imai, M., H. Shimida, Y. Watanabe, Y. Matsushima-Hibiya, R. Makino, H. Koga, T. Horiuchi, and Y. Ishimura. 1989. Uncoupling of the cytochrome P-450cam monooxygenase reaction by a single mutation, threonine- 252 to alanine or valine: A possible role of the hydroxy amino acid in oxygen activation. Proc. Natl. Acad. Sci. 86: 7823-7827.

Imai, Y. and M. Nakamura. 1988. The importance of threonine301 from cytochrome P-450 (laurate $(\omega-1)$-hydroxylase and testosterone $16 \alpha$-hydroxylase) in substrate binding as demonstrated by site-directed mutagenesis. FEBS Lett. 234: 313-315.

Kalb, V.F. and J.C. Loper. 1988. Proteins from eight eukaryotic cytochrome P-450 families share a segmented region of sequence similarity. Proc. Natl. Acad. Sci. 85: 7221-7225.

Kalb, V.F., C.W. Woods, T.G. Turi, C.R. Dey, T.R. Sutter, and
J.C. Loper. 1987. Primary structure of the lanosterol demethylase gene from Saccharomyces cerevisiae. DNA 6: $529-537$.

Kassir, Y. and G. Simchen. 1976. Regulation of mating and meiosis in yeast by the mating type locus. Genetics 82: 187-206.

Kassir, Y., D. Granot, and G. Simchen. 1988. IME1, a positive regulator gene of meiosis in S. cerevisiae. Cell 52: 853-862.

Katohda, S., K. Konno, Y. Sasaki, K. Suzuki, and S. Sakamoto. 1984. Isolation and composition of the spore wall of Saccharomyces cerevisiae. Agr. Biol. Chem. 48: 895-901.

Kreger-van Rij, N.J.W. 1978. Electron microscopy of germinating ascospores of Saccharomyces cerevisiae. Arch. Microbiol. 117: 73-77.

Kurtz, S. and S. Lindquist. 1984. Changing patterns of gene expression during sporulation in yeast. Proc. Natl. Acad. Sci. 81: $7323-7327$.

1986. Subcellular differentiation in sporulating yeast cells. Cell 45: $771-779$.

Law, D.T.S. and J. Segall. 1988. The SPS100 gene of Saccharomyces cerevisiae is activated late in the sporulation process and contributes to spore wall maturation. Mol. Cell. Biol. 8: 912-922.

Lynn, R.R. and P.T. Magee. 1970. Development of the spore wall during ascospore formation in Saccharomyces cerevisiae. I. Cell Biol. 44: 688-692.

Magee, P.T. 1987. Transcription during meiosis. In Meiosis (ed. P. Moens|, p. 355. Academic Press, New York.

Maniatis, T., E.F. Fritsch, and J. Sambrook. 1982. Molecular cloning: A laboratory manual. Cold Spring Harbor Laboratory, Cold Spring Harbor, New York.

Mitchell, A.P. and I. Herskowitz. 1986. Activation of meiosis and sporulation by repression of the $R M E 1$ product in yeast. Nature 319: 738-742.

Moens, P.B. 1971. Fine structure of ascospore development in the yeast Saccharomyces cerevisiae. Can. I. Microbiol. 17: $507-510$.

Nasmyth, K.A. and K. Tatchell. 1980. The structure of transposable yeast mating type loci. Cell 19: 753-764.

Nebert, D.W., D.R. Nelson, M. Adesnik, M.J. Coon, R.W. Estabrook, F.J. Gonzalez, F.P. Guengerich, I.C. Gunsalus, E.F. Johnson, B. Kemper, W. Levin, I.R. Phillips, R. Sato, and M.R. Waterman. 1989. The P-450 superfamily: Updated listing of all genes and recommended nomenclature for the chromosomal loci. DNA 8: 1-13.

Ortiz de Montellano, P., ed. 1986. Oxygen activation and transfer. In Cytochrome P-450; structure, mechanism and biochemistry, pp. 217-271. Plenum Press, New York/ London.

Pearson, W.R. and D.J. Lipman. 1988. Improved tools for biological sequence comparison. Proc. Natl. Acad. Sci. 85: 24442448.

Percival-Smith, A. and J. Segall. 1984. Isolation of DNA sequences preferentially expressed during sporulation in Saccharomyces cerevisiae. Mol. Cell. Biol. 4: 142-150.

- 1986. Characterization and mutational analysis of a cluster of three genes expressed preferentially during sporulation in Saccharomyces cerevisiae. Mol. Cell. Biol. 6: $2443-2451$.

Poulos, T.L., B.C. Finzel, I.C. Gunsalus, G.C. Wagner, and J. Kraut. 1985. The 2.6- $\AA$ crystal structure of Pseudomonas putida cytochrome P-450. J. Biol. Chem. 260: 16122-16130.

Put, H.M.C. and J. De Jong. 1981. The heat resistance of ascospores of Saccharomyces cerevisiae. J. Appl. Bacteriol. 52: 235-241.

Rockmill, B. and S. Fogel. 1988. DIS1: A yeast gene required for 
proper meiotic chromosome disjunction. Genetics 119: $262-272$.

Rockmill, B. and G.S. Roeder. 1988. RED1: A yeast gene required for the segregation of chromosomes during the reductional division of meiosis. Proc. Natl. Acad. Sci. 85: 60576061.

Rothstein, R. 1983. One-step gene replacement in yeast. Methods Enzymol. 101: 202-211.

Sanger, F., S. Nicklen, and A.R. Coulson. 1977. DNA sequencing with chain-terminating inhibitors. Proc. Natl. Acad. Sci. 74: 5463-5467.

Sherman, F., G.R. Fink, and J.B. Hicks. 1986. Methods in yeast genetics. Cold Spring Harbor Laboratory, Cold Spring Harbor, New York.

Smith, H.E. and A.P. Mitchell. 1989. A transcriptional cascade governs entry into meiosis in Saccharomyces cerevisiae. Mol. Cell. Biol. 9: 2142-2152.

Thompson, E.A. and G.S. Roeder. 1989. Expression and DNA sequence of $R E D 1$, a gene required for meiosis I chromosome segregation in yeast. Mol. Gen. Genet. 218: 293-301.

Tsuboi, M. 1983. The isolation and genetic analysis of sporulation-deficient mutants in Saccharomyces cerevisiae. Mol. Gen. Genet. 191: 17-21.

Wagstaff, J.E., S. Klapholz, and R.E. Esposito. 1982. Meiosis in haploid yeast. Proc. Natl. Acad. Sci. 79: 2986-2990.

Wang, H.-T., S. Frackman, J. Kowalisyn, R.E. Esposito, and R.T. Elder. 1987. Developmental regulation of SPO13, a gene required for separation of homologous chromosomes at meiosis I. Mol. Cell. Biol. 7: 1425-1435.

Weir-Thompson, E.M. and I.W. Dawes. 1984. Developmental changes in translatable RNA species associated with meiosis and spore formation in Saccharomyces cerevisiae. Mol. Cell. Biol. 4: 695-702.

Yamashita, I. and S. Fukui. 1985. Transcriptional control of the sporulation-specific glucoamylase gene in the yeast Saccharomyces cerevisiae. Mol. Cell. Biol. 5: 3069-3073.

Zuber, M.X., M.E. John, T. Okamura, E.R. Simpson, and M.R. Waterman. 1986. Bovine adrenocortical cytochrome P- $450_{17 \alpha}$. Regulation of the gene expression by ACTH and elucidation of primary sequence. J. Biol. Chem. 261: 24752482 . 


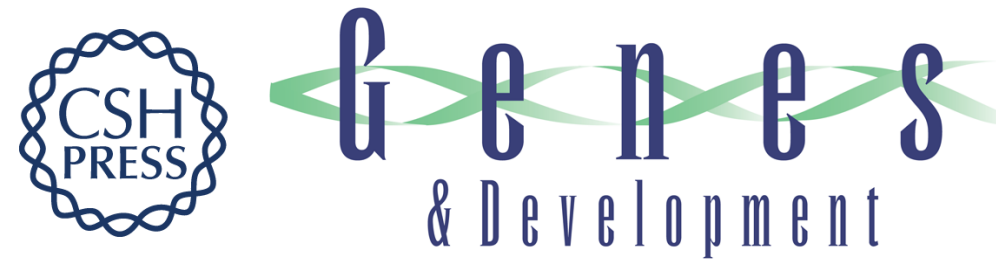

\section{Isolation of two developmentally regulated genes involved in spore wall maturation in Saccharomyces cerevisiae.}

P Briza, M Breitenbach, A Ellinger, et al.

Genes Dev. 1990, 4:

Access the most recent version at doi:10.1101/gad.4.10.1775

References This article cites 53 articles, 32 of which can be accessed free at:

http://genesdev.cshlp.org/content/4/10/1775.full.html\#ref-list-1

License

Email Alerting

Service

Receive free email alerts when new articles cite this article - sign up in the box at the top right corner of the article or click here.

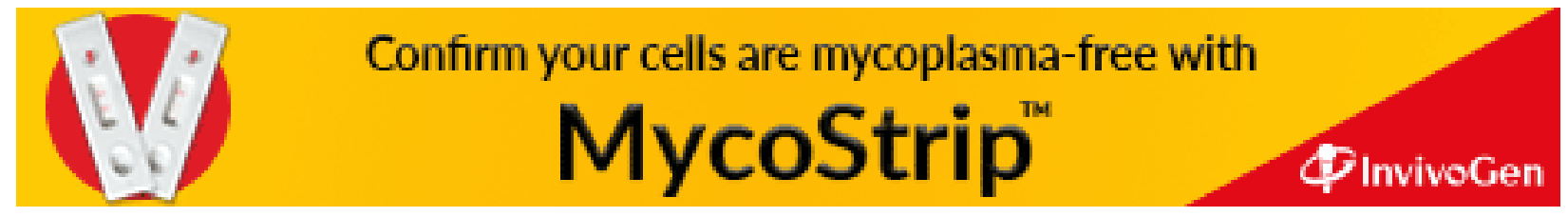

